\title{
Tejido óseo, una nueva alternativa en agregados para el concreto
}

Bone tissue, a new alternative in aggregates for concrete

Tecido ósseo, um novo alternativa em agregados para concreto

\section{Jaime Iván Mora Samacá ${ }^{1}$}

Recibido: agosto 20 de 2018

Aprobado: noviembre 12 de 2018

Disponible en línea: enero 15 de 2019

Cómo citar este artículo:

J. I. Mora, "Tejido óseo, una nueva alternativa en agregados para el concreto", Revista Ingeniería Solidaria, vol. 25, n. ${ }^{\circ} 1,2019$.

DOI: https://doi.org/10.16925/2357-6014.2019.01.07 


\section{Resumen}

Introducción: el artículo "Tejido óseo, una nueva alternativa en agregados para el concreto" es producto de la investigación en proceso "Tejido óseo en el concreto", realizada dentro del programa de Ingeniería Civil de la universidad Piloto desde el año 2016.

Antecedentes: al observar estudios de funcionamiento y propiedades físico-mecánicas del hueso, este es identificado como un material apropiado para incluir dentro de la mezcla del mortero, lo cual ya fue realizado desde el año 2012 por algunos investigadores, con resultados en pro de la investigación.

Metodología: la resistencia y propiedades físico-mecánicas, del tejido óseo abren un umbral de posibilidades para su utilización dentro del concreto, que procesado por medio de la calcinación muestra una alternativa para ser adjuntado en la pasta de cemento.

Resultados: las pruebas hechas a compresión en la pasta de cemento, arrojan unos resultados favorables reemplazando $10 \%$ el material cementante por hueso calcinado una hora a $1200^{\circ} \mathrm{C}$.

Discusión: el tejido óseo es apto para utilizar de diferentes formas, dentro de la mezcla con un tratamiento previo.

Conclusiones: el hueso calcinado una hora a $1200^{\circ} \mathrm{C}$ tiene propiedades físicas muy similares a las del cemento. El reemplazo del 10\% genera mayor resistencia que la mezcla pura.

Limitaciones: no hay una estandarización para el procesamiento del elemento óseo. La información acerca del tema es escaza con resultados repetitivos.

Originalidad: el tratamiento del hueso por medio de la calcinación, variando los tiempos y la temperatura es un método sin precedentes.

Palabras clave: mortero, concreto, cemento, hueso, ganado, calcinación.

\section{Abstract}

Introduction: The article bone tissue a new alternative in aggregates for concrete is the product of the research in process "Bone tissue in concrete", carried out within the Civil Engineering program of the Piloto University since 2016

Antecedents: Observing performance studies and physical-mechanical properties of bone, this is identified as an appropriate material to be included in the mortar mix, which has been done since 2012 by some researchers, with results in favor of research.

Methodology: The resistance and physical-mechanical properties of the bone tissue open a threshold of possibilities for its use within the concrete, which processed by means of calcination shows an alternative to be attached to the cement paste.

Results: The compression tests in the cement paste, give favorable results replacing $10 \%$ the cementing material for bone calcined at $1200^{\circ} \mathrm{C}$ for one hour.

Discussion: The bone tissue is apt to be used in different ways, within the mixture with a previous treatment.

Conclusions: Calcined bone one hour at $1200^{\circ} \mathrm{C}$ has physical properties very similar to those of cement. The $10 \%$ Replacement generates greater resistance than the pure mixture.

Limitations: There is no standardization for bone element processing. Information about the subject is scanty with repetitive results.

Originality: The treatment of the bone by means of calcination, varying the times and the temperature is an unprecedented method.

Keywords: Resistance- concrete- bone- mortar- livestock- organic- inorganic properties 


\section{Resumo}

Introdução: O artigo do tecido ósseo uma nova alternativa em agregados para concreto é o produto da pesquisa em processo "tecido ósseo em concreto", realizada dentro do programa de Engenharia Civil da Universidade piloto desde 2016

Background: Observando estudos de desempenho e propriedades físico-mecânicas do osso Isto é identificado como um material adequado para incluir na mistura de argamassa que já foi realizado desde 2012 por alguns pesquisadores, com resultados em matéria de investigação .

Metodologia: A resistência e as propriedades físico-mecânicas do tecido ósseo abrem um limiar de possibilidades para seu uso dentro do concreto, que processado por meio de calcinação mostra uma alternativa a ser anexada à pasta de cimento.

Resultados: Os testes de compressão na pasta de cimento dão resultados favoráveis, substituindo $10 \%$ do material de cimentação por uma hora calcinada no osso a $1200^{\circ} \mathrm{C}$.

Discussão: 0 tecido ósseo está apto a ser usado de diferentes maneiras, dentro da mistura com um tratamento prévio.

Conclusões: 0 osso calcinado por uma hora a $1200^{\circ} \mathrm{C}$ tem propriedades físicas muito semelhantes às do cimento. A substituição de 10\% gera mais resistência do que a mistura pura.

Limitações: Não há padronização para o processamento do elemento ósseo. As informações sobre o assunto são escassas com resultados repetitivos.

Originalidade: 0 tratamento do osso por meio de calcinação, variando os tempos e a temperatura é um método sem precedentes.

Palavras-chave: argamassa, concreto, cimento, osso, gado, calcinação.

\section{Introducción}

Desde inicios del siglo XX, el concreto es el elemento de mayor uso dentro del ámbito de la construcción por su fácil adaptación a la necesidad que presente la estructura, sin embargo hasta el día de hoy no se ha logrado superar sus dos principales debilidades que son la resistencia a la tracción y el módulo de elasticidad, los cuales son manejados por medio de métodos deconstructivos o aditivos, que elevan los costos. En búsqueda de disminuir costos y aumentar sus propiedades, se está buscando un material innovador, económico y de fácil acceso que se pueda agregar al concreto suplantando parte o completamente alguno de sus agregados.

Al realizar una búsqueda exhaustiva, se encontró en el tejido óseo este material, el cual a pesar que cuenta con las propiedades físicas y químicas de varios de los agregados del concreto, presenta algunas deficiencias que se deben investigar a profundidad para que sean superadas y mirar hasta qué punto y de qué forma, este elemento puede ser introducido dentro de la mezcla de mortero para elevar su estándar de calidad. 


\section{Antecedentes de investigación}

La búsqueda de la excelencia de los materiales en el ámbito de la construcción, durante las últimas décadas van de la mano del ahorro y la conservación del medio ambiente, la cual encuentra en el reciclaje un apoyo; es por eso que tras realizar una búsqueda exhaustiva, se encontró en el sistema óseo de todo ser viviente un material óptimo y adaptable, lo cual se pudo verificar al revisar más de doce artículos en inglés y español que datan del año 2012 al 2017, junto a más de dieciséis textos de formación profesional que permitieron ver en el hueso un elemento que cuenta con propiedades mecánicas, físicas y químicas aptas para ser incluidas dentro de la mezcla de mortero.

\subsection{Propiedades del tejido óseo y su uso dentro del mortero}

El comportamiento biomecánico del hueso dentro del cuerpo del ser viviente permite hacer de este un elemento estructural de alta resistencia como lo comprueban Caeiro, González y Guede [1], [2], quienes muestran detalladamente cómo trabajan los huesos. A parte de eso, la resistencia del hueso es demostrada por el ingeniero A. Mendoza [3], que pone en evidencia las propiedades físico-mecánicas del tejido óseo humano dejando clara su alta resistencia a compresión y tensión. Aunque estos dos componentes investigativos son ajenos al ámbito de la construcción, permiten abrir un gran interrogante acerca de si este material es apto para utilizar como un agregado más del concreto.

Al clasificar los agregados del concreto como lo muestra Sánchez de Guzmán [4] y al compararlos con las propiedades del hueso [1], [3], se encuentran varias semejanzas y diferencias que pueden ser perfeccionadas, y si se confronta la resistencia a compresión y tensión del hueso con los tipos de concreto que plantea Mora Samacá [5] y Segura Franco [6], se puede identificar en el tejido óseo un material apto para ser parte del mortero. Junto con estas dos comparaciones en los textos [4], [5] y [6] al mostrar las propiedades del concreto, es notorio que su resistencia a la tensión no alcanza a ser el 12\% de la resistencia a la compresión, lo que es totalmente diferente en el tejido óseo en el cual la resistencia a la tensión tiene 20Mpa de diferencia bajo la resistencia a la compresión. No se sabe hasta qué punto estas virtudes fueron notadas por otros profesionales, ya que en la búsqueda de documentación, es escaza la información de investigaciones que han utilizado el hueso dentro de la mezcla; los documentos encontrados arrojan resultados en pro y en contra del tejido óseo, se resaltan diez de los doce artículos que hablan del hueso como parte de alguno de los 
agregados, esto muestra a este material como un elemento favorable para la mezcla, aunque solo en tres de ellos [10], [12], [14] los resultados arrojan cifras favorables por encima de la mezcla pura ( $0 \%$ de hueso).

De los artículos que tratan directamente el tema de reemplazos de hueso por alguno de los agregados del concreto, sobresalen diez por los detalles entregados, no solo en cuanto a la resistencia del concreto, sino también en temas económicos, patológicos, contenido de agua y tiempos de fraguado [7], [8], [9], [10], [11], [12], [13], [14], [15], [16], los demás artículos entregan resultados repetitivos o confusos. Por eso, si se mira la investigación hecha por Falade, Ikponmwosa y Fapohunda [7] se evidencia que califican el polvo de hueso bobino como una puzolana, razón por la cual se hacen reemplazos parciales de cemento por este material, lo que da unos resultados de resistencia inferiores a la muestra pura, con una serie de fisuraciones sobre la probeta. Por su parte otros investigadores [8] con la misma metodología, también entregan resultados por debajo de la muestra pura recalcando que un reemplazo entre el 10\% y $15 \%$ es una cifra idónea para que sea utilizada dentro de la mezcla, así no se alcance la resistencia máxima de la mezcla pura.

No todas las muestras con reemplazos parciales arrojan resultados por debajo de la muestra pura donde es el caso de [10] que aparte de superar la resistencia de los especímenes del 0\%, encuentran en el reemplazo del 7,5\% la cantidad perfecta y de mayor resistencia, mostrando una similitud porcentual al de la anterior investigación [8] y que se repite por Akinyele, Adekunle, y Ogundaini [12], quienes entregan con este porcentaje de reemplazo una resistencia mayor a la de la muestra pura durante los 4 tiempos de hidratación, junto a los resultados, estos investigadores dan la composición química del hueso permitiendo calificarlo como una puzolana tipo C.

Pero no todos los autores comparten la misma teoría, ya que Okoye y Odumodu [13] contradicen lo que dicho por Akinyele, Adekunle, y Ogundaini [12], y con estudios de composición química y una serie de especímenes, sustentan que el hueso pulverizado no es una puzolana; junto a esto, muestran unos resultados de resistencia por debajo de los especímenes del 0\%, pero aun así reafirman que el 10\% es un reemplazo ideal, lo mismo que Navya [14], quien obtuvo resultados superiores a los de la mezcla reemplazando, a diferencia de los demás autores [7], [8], [9], [10], [12], [13], [14], el agregado grueso por hueso triturado y no el cemento.

A pesar de que todos los autores citados muestran en el uso del hueso un factor positivo Ogarekpe et al. [11] hacen del hueso calcinado un elemento negativo no solo por su baja resistencia si no por mayor consumo de agua, largos tiempos de fraguado y factores patológicos, lo cual es contradicho por los autores anteriores y por Monroy C.; Ríos C.; Ospina J.D.; Ortiz N.; Villa J. [17] quienes entregan en el hueso calcinado 
un excelente material de reemplazo, con unos resultados de resistencia superiores a la muestra pura en todos los tiempos de hidratación, estos reemplazos con hueso calcinado y con buenos resultados es reforzada por Varma et al. [9], quienes muestran en los reemplazos superiores al 10\% un error, ya que al superar este porcentaje la muestra empieza a perder resistencia.

\subsection{Componentes orgánicos e inorgánicos del sistema óseo}

El hueso es una matriz con componentes orgánicos e inorgánicos, los cuales cumplen una función estructural y de auto reparación sobre todo ser viviente, para su uso en el concreto se debe recurrir a la parte inorgánica, ya que todo elemento orgánico sobre el concreto puede generar una falla al alcanzar el estado de descomposición [4].

\subsubsection{Componentes inorgánicos}

El hueso está compuesto en su matriz por sales minerales que se encuentran en una retícula formada por fibras de colágeno, la cuales están constituidas en un 60\% a 70\% por hidroxiapatita o fosfato tricálcico $\left[\mathrm{Ca}_{10}\left(\mathrm{PO}_{4}\right)_{6} .(\mathrm{OH})_{2}\right]$ el cual cuenta con un 99\% de depósito de calcio y un 80\% de fósforo [1]. Acorde a lo dicho por [1], a menor escala de hidróxido de magnesio, carbono cálcico y sulfatos, esta matriz inorgánica permite una mayor resistencia a la compresión.

\subsubsection{Componentes orgánicos}

Son los encargados de dar flexibilidad y elasticidad al hueso, oscilan entre 30\% y $40 \%$ de la masa total. El 10\% del componente orgánico es agua y el restante es colágeno tipo I. Otros componentes orgánicos como la osteonectina (SPRC o BM-40) es una fosfoproteína que se encuentra dispersa por todo el hueso de manera aleatoria interactuando con el colágeno y con sales inorgánicas, la función principal de la osteopontina o sialoproteína es el crecimiento del sistema óseo [2].

\subsubsection{Propiedades mecánicas del hueso humano}

Aunque hay varios autores que han investigado acerca de las propiedades mecánicas del hueso reconociendo su resistencia a la compresión, tensión y los componentes 
que permiten que estas resistencias sean posibles; para la finalidad de esta investigación, llaman la atención los estudios realizados por el ingeniero Álvaro Mendoza de la Universidad Nacional de Colombia [3], quien por medio de probetas adaptadas a la máquina universal realizó pruebas de tracción y compresión, con muestras de hueso fresco (tibia, fémur, peroné) suministrado por el Hospital San Juan de Dios.

Resistencia a la compresión:

Tabla 1. Propiedades mecánicas a la compresión tejido óseo

\begin{tabular}{lcc}
\hline \multicolumn{1}{c}{ PROPIEDAD } & MAGNITUD & UN \\
\hline Resistencia última & 107,5 & $\mathrm{MPa}$ \\
\hline Esfuerzo de fluencia & 86,9 & $\mathrm{MPa}$ \\
\hline Módulo de elasticidad & 10,8 & $\mathrm{GPa}$ \\
\hline Deformación elástica & 0,85 & $\%$ \\
\hline Deformación total & 180 & $\%$ \\
\hline
\end{tabular}

Fuente: A. Mendoza [3]

\section{Diagrama Esfuerzo Compresión}

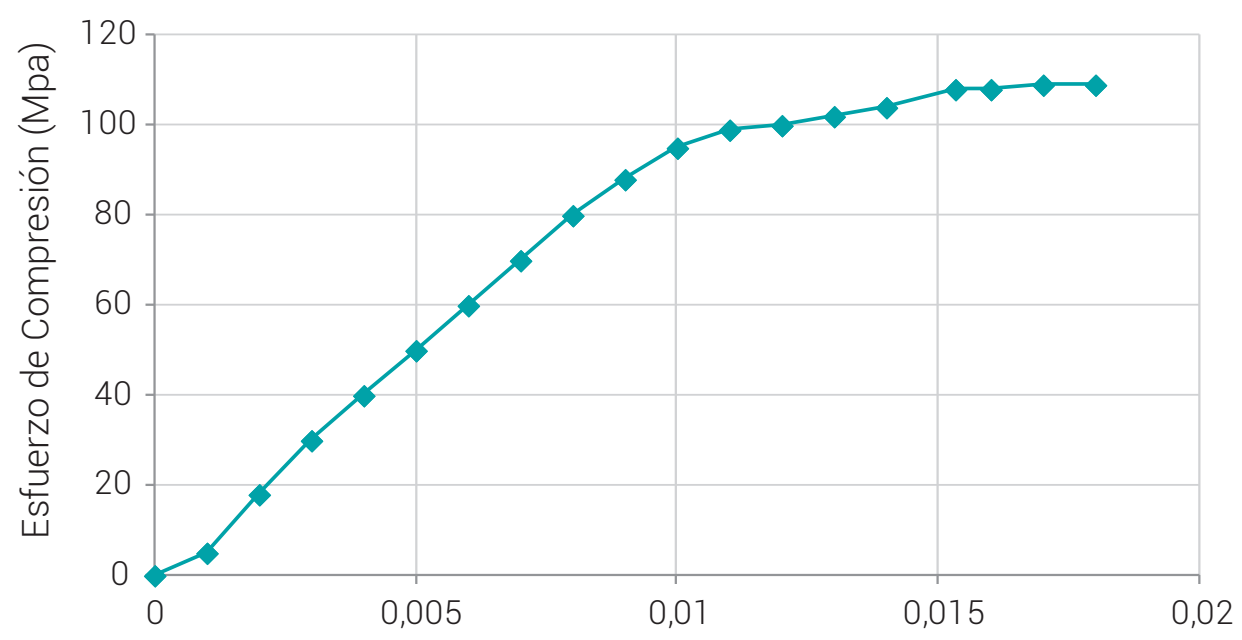

Deformación

Figura 1. Propiedades mecánicas a compresión tejido óseo

Fuente: A. Mendoza [3] 
Resistencia a la tracción:

Tabla 2. Propiedades mecánicas a la tracción tejido óseo

\begin{tabular}{lcc}
\hline \multicolumn{1}{c}{ PROPIEDAD } & MAGNITUD & UN \\
\hline Resistencia última & 76,6 & Mpa \\
\hline Esfuerzo de fluencia & 69,2 & Mpa \\
\hline Módulo de elasticidad & 7,7 & $\mathrm{Gpa}$ \\
\hline Deformación elástica & 0,8 & $\%$ \\
\hline Deformación total & 1 & $\%$ \\
\hline Energía elástica & 0,31 & $\mathrm{MJ} / \mathrm{m} 3$ \\
\hline Energía absorbida & 0,17 & $\mathrm{MJ} / \mathrm{m} 4$ \\
\hline
\end{tabular}

Fuente: A. Mendoza [3]

\section{Diagrama Esfuerzo Tracción}

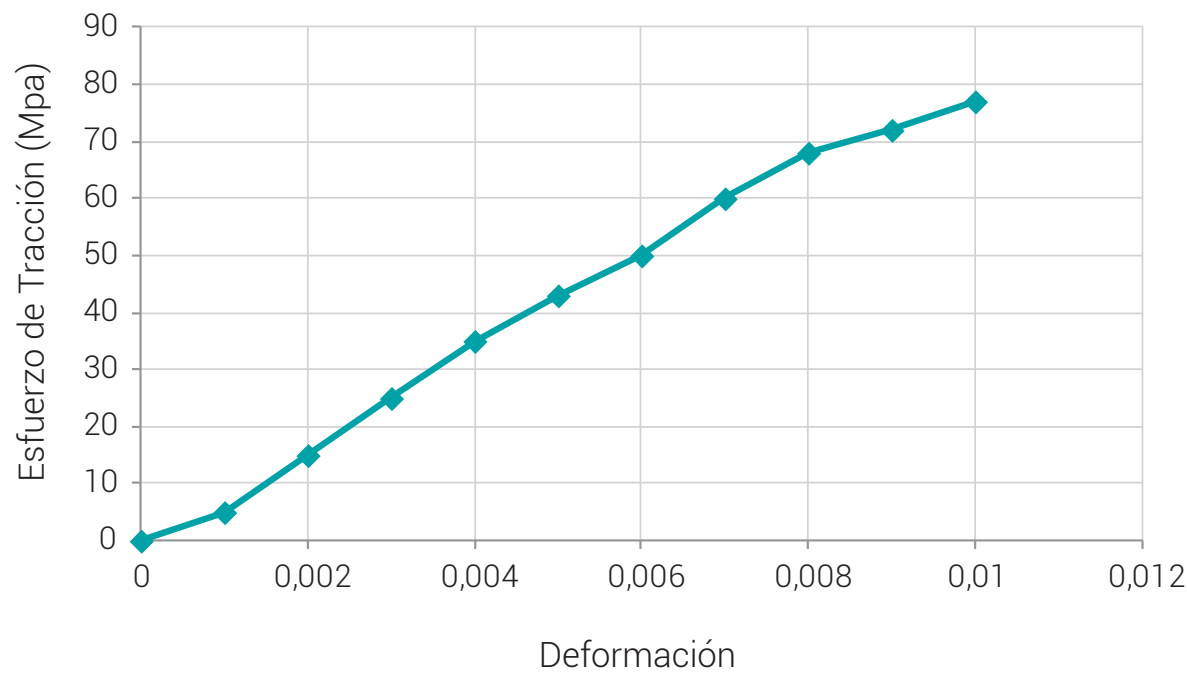

Figura 2. Propiedades mecánicas a tracción tejido óseo

Fuente: A. Mendoza [3]

Otra investigación que sirvió de inspiración, fue la realizada por Caeiro, González y Guede, "Ensayos en los distintos niveles jerárquicos del hueso y técnicas alternativas para la determinación de la resistencia ósea" [1], donde se tomó el hueso cortical haciendo probetas cilíndricas y cúbicas con un número suficiente de sistemas Havers y huecos intersticiales, lo cual depende de la región de donde se extrajo la muestra. Cabe resaltar que se eligió el hueso cortical para estos ensayos por su ubicación 
dentro de las articulaciones permitiendo un alto nivel de compactación abarcando el $80 \%$ del sistema óseo, dejando un 20\% restante de hueso trabecular o esponjoso.

De la misma manera que un miembro tubular en una estructura presenta una gran resistencia cuando se le aplica una carga axial, el hueso cortical, presenta una mayor resistencia cuando se aplican cargas longitudinales a $0^{\circ}$ de inclinación, que transversales a $90^{\circ}$, esto permite deducir que el hueso trabaja de manera tubular donde el sistema cortical es el responsable de brindar un $60 \%$ de la resistencia del hueso entero.

Tabla 3. Valores de resistencia máxima y módulo elástico del hueso cortical humano para los distintos tipos de ensayos mecánicos

\begin{tabular}{lll}
\hline \multirow{2}{*}{ Ensayos de compresión } & Resistencia & $167-213 \mathrm{MPa}$ \\
\cline { 2 - 3 } Ensayos de tracción & Módulo de young & $14,7-34,3 \mathrm{GPa}$ \\
\hline \multirow{2}{*}{ Ensayos de flexión } & Resistencia & $107-170 \mathrm{MPa}$ \\
\cline { 2 - 3 } & Módulo de young & $11,4-29,2 \mathrm{GPa}$ \\
\hline \multirow{2}{*}{ Ensayos de torsión } & Resistencia & $103-238 \mathrm{MPa}$ \\
\cline { 2 - 3 } & Módulo de young & $9,8-15,7 \mathrm{GPa}$ \\
\hline
\end{tabular}

Fuente: Caeiro, Gonzáles y Guede [1]

\subsection{Aciertos y fallas en la utilización del hueso dentro de la mezcla de concreto}

Los ingenieros Falade, Ikponmwosa y Fapohunda [7] han buscado dar uso al hueso bovino pulverizado para aprovechar sus propiedades puzolánicas, haciendo reemplazos parciales de cemento para medir la flexión y compresión en vigas estándar de $15 * 75 * 75 \mathrm{~cm}$, lo que ha arrojado resultados satisfactorios, pero que no superan los resultados dados por una mezcla pura de concreto, mostrando un comportamiento patológico acorde al porcentaje de hueso pulverizado donde a mayor porcentaje de hueso pulverizado, aparecían de una manera más temprana las fisuraciones (tabla 4), y esto daba como resultado una menor resistencia a la tracción, donde los autores afirman que por consiguiente también se presenta una menor resistencia a la compresión. Estas fisuras también mostraban mayor variedad en forma y longitud, a medida que el hueso era incrementado dentro de la mezcla. 
Tabla 4. Comparación entre los momentos flectores experimentales y teóricos

\begin{tabular}{cccccccc}
\hline \% PB & $\begin{array}{c}\text { Carga } \\
\text { primera } \\
\text { fisura } \\
\text { (KN) }\end{array}$ & $\begin{array}{c}\text { Carga } \\
\text { de falla } \\
(\mathbf{K N})\end{array}$ & $\begin{array}{c}\text { Disminución } \\
\text { de la carga } \\
\text { de falla }\end{array}$ & $\begin{array}{c}\text { Carga de } \\
\text { servicio } \\
\text { (KN) }\end{array}$ & $\begin{array}{c}\text { Momento } \\
\text { de diseño } \\
\text { tehorico } \\
\text { (KN.m) }\end{array}$ & $\begin{array}{c}\text { Momento } \\
\text { último } \\
\text { experimental } \\
\text { (KN.m) }\end{array}$ & $\frac{\boldsymbol{M}_{\text {EXP }}}{\boldsymbol{M}_{\boldsymbol{B S}}}$ \\
\hline 0 & $75,00 \pm 0,50$ & $92,5 \pm 0,96$ & - & 46,88 & 4,13 & 4,4 & 1,07 \\
\hline 5 & $70,00 \pm 1,50$ & $87,50 \pm 1,32$ & 5,4 & 43,75 & 3,88 & 4,1 & 1,06 \\
\hline 10 & $70,00 \pm 0,87$ & $85,00 \pm 1,31$ & 8,1 & 43,75 & 3,75 & 4,1 & 1,09 \\
\hline 15 & $65,00 \pm 0,50$ & $80,00 \pm 0,87$ & 13,5 & 40,63 & 3,55 & 3,81 & 1,07 \\
\hline 20 & $62,50 \pm 0,50$ & $72,50 \pm 0,87$ & 21,6 & 39,06 & 3,48 & 3,66 & 1,05 \\
\hline
\end{tabular}

Fuente: Falade, Ikponmwosa y Fapohunda [7]

Los autores también muestran una gran desventaja en la deflexión que aumenta a medida que se incrementa el contenido de hueso dejando como mayor resistencia el concreto con $0 \%$ de agregado óseo.

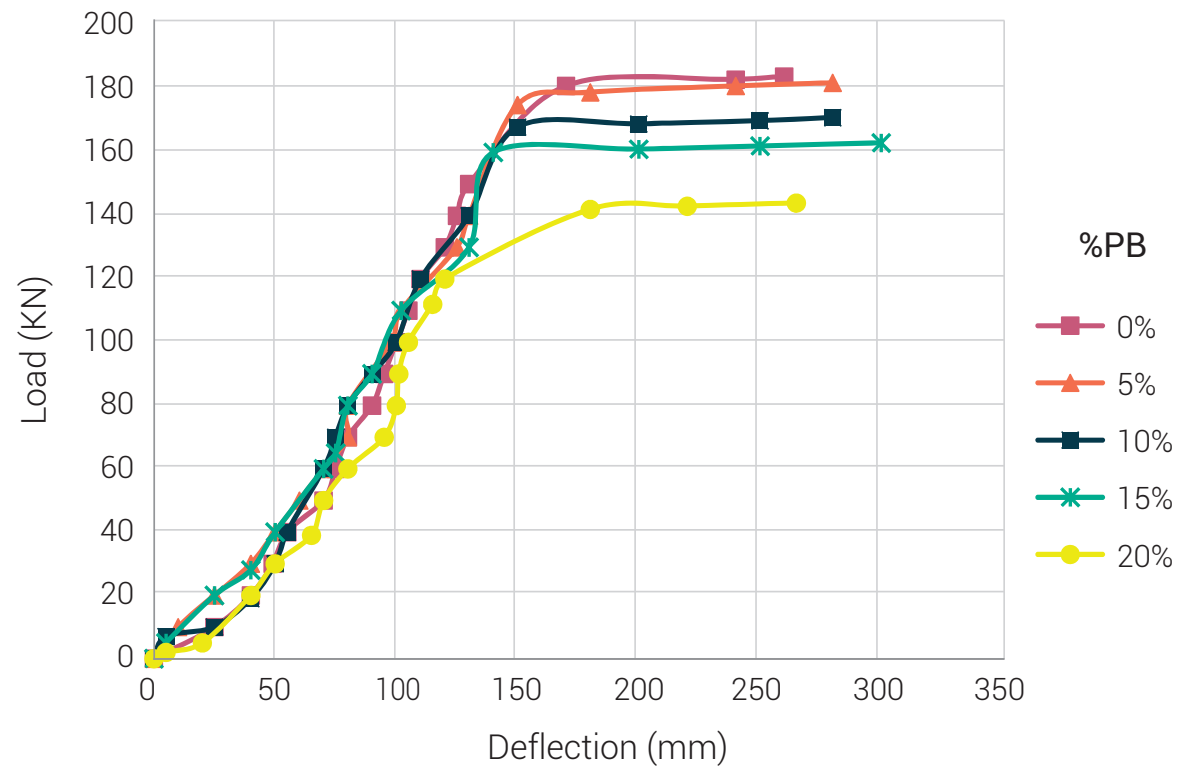

Figura 3. Carga de deflexión para todos los reemplazos de cemento con hueso pulverizado

Fuente: Falade, Ikponmwosa y Fapohunda [7]

Junto a esto, el hueso pulverizado en concreto espumoso es utilizado en "Evaluation of strength relations in foamed aerated concrete containing pulverized bone" [8]; muestra el mismo comportamiento porcentual donde a mayor porcentaje de hueso menor resistencia, y entrega unos resultados con mayor detalle de la resistencia a la compresión y tensión (tablas 5 y 6) tomando el mismo tipo de probetas con 
las que se hicieron las pruebas en "Flexural performance of foam concrete containing pulverised bone as partial replacement of cement" [7], donde se demostró que a mayor días de curado mayor resistencia a la compresión y a la tensión, pero ninguna de las pruebas hechas a vigas con agregado óseo supera la resistencia del 0\%. Estos investigadores [8] recalcan que un porcentaje entre el 10\% y 15\% es idóneo para el reemplazo de hueso.

Tabla 5. Resistencia a la compresión y tensión a los 28 días de curado

\begin{tabular}{cccccc}
\hline \% PB & $\begin{array}{c}\text { Resistencia a la } \\
\text { compresión } \\
\mathbf{( K N / m m 2 )}\end{array}$ & $\begin{array}{c}\text { Resistencia a } \\
\text { la tensión } \\
\mathbf{( K N / m m 2 )}\end{array}$ & $\begin{array}{c}\text { Radio } \\
\boldsymbol{\alpha}=\frac{\boldsymbol{f s}}{\boldsymbol{f c}}\end{array}$ & $\begin{array}{c}\text { Módulo de } \\
\text { rotura } \\
\mathbf{( N / m m 2 )}\end{array}$ & $\begin{array}{c}\text { Radio } \\
\boldsymbol{f r}\end{array}$ \\
\hline 0 & $15,93(13,12) \pm 0,51$ & $1,84 \pm 0,04$ & 0,14 & $2,81 \pm 0,07$ & $\mathbf{f c}$ \\
\hline 5 & $15,01(12,10) \pm 0,40$ & $1,66 \pm 0,10$ & 0,14 & $2,58 \pm 0,05$ & 0,21 \\
\hline 10 & $14,21(11,91) \pm 0,20$ & $1,58 \pm 0,07$ & 0,13 & $2,21 \pm 0,00$ & 0,19 \\
\hline 15 & $13,87(11,62) \pm 0,29$ & $1,32 \pm 0,04$ & 0,12 & $2,05 \pm 0,02$ & 0,18 \\
\hline 20 & $13,00(11,03) \pm 0,83$ & $1,11 \pm 0,00$ & 0,1 & $1,89 \pm 0,09$ & 0,17 \\
\hline
\end{tabular}

Fuente: Falade, Ikponmwosa y Fapohunda [8]

Tabla 6. Resistencia a la compresión y tensión a los 90 días de curado

\begin{tabular}{cccccc}
\hline \% PB & $\begin{array}{c}\text { Resistencia a } \\
\text { la Compresión } \\
(\mathbf{K N} / \mathbf{m m} \mathbf{)})\end{array}$ & $\begin{array}{c}\text { Resistencia a } \\
\text { la Tensión } \\
\mathbf{( K N / m m 2 )}\end{array}$ & $\begin{array}{c}\text { Radio } \\
\boldsymbol{\alpha}=\frac{\boldsymbol{f s}}{\boldsymbol{f c}}\end{array}$ & $\begin{array}{c}\text { Módulo de } \\
\text { Rotura } \\
\mathbf{( N / m m 2 )}\end{array}$ & $\begin{array}{c}\text { Radio } \\
\boldsymbol{f r}\end{array}$ \\
\hline 0 & $18,25(15,26) \pm 0,33$ & $2,68 \pm 0,03$ & 0,18 & $2,94 \pm 0,00$ & $\mathbf{\beta} \mathbf{f c}$ \\
\hline 5 & $17,68(14,18) \pm 0,28$ & $2,39 \pm 0,00$ & 0,17 & $2,82 \pm 0,03$ & 0,2 \\
\hline 10 & $16,88(14,01) \pm 0,03$ & $2,14 \pm 0,02$ & 0,15 & $2,75 \pm 0,03$ & 0,22 \\
\hline 15 & $15,69(12,46) \pm 0,64$ & $1,91 \pm 0,07$ & 0,15 & $2,69 \pm 0,00$ & 0,22 \\
\hline 20 & $14,88(12,10) \pm 0,23$ & $1,79 \pm 0,00$ & 0,15 & $2,66 \pm 0,00$ & 0,17 \\
\hline
\end{tabular}

Fuente: Falade, Ikponmwosa y Fapohunda [8]

Por su parte los investigadores Ahmad, Ahmad y Kashif [10], que sobresalen al asegurar que el concreto con hueso pulverizado, tiene potencial para ser aplicado estructuralmente, lo cual fue comprobado en probetas cúbicas de $15 \mathrm{~cm}$ sometidas a compresión con 7 porcentajes diferentes de reemplazo de cemento y conservación de los demás componentes de la mezcla (tabla 7), que superaron la resistencia a compresión en muestras con $0 \%$ de hueso pulverizado, lo que mostró la mayor resistencia en especímenes con un reemplazo del 7,5\%; esto resalta que al superar este porcentaje el concreto ya empieza a mostrar disminución en su resistencia. 
Tabla 7. Resistencia a la compresión de probetas con reemplazo parcial de cemento por hueso

\begin{tabular}{|c|c|c|}
\hline$\%$ de hueso pulverizado & $\begin{array}{c}\text { Fuerza a compresión } \\
(\mathrm{N} / \mathrm{mm} 2)\end{array}$ & $\begin{array}{c}\text { Fuerza a compresión } \\
(\mathrm{N} / \mathrm{mm} 2)\end{array}$ \\
\hline & 7 dias & 28 dias \\
\hline 0,0 & 23,33 & 32,44 \\
\hline 1,5 & 23,46 & 33,52 \\
\hline 3,0 & 24,10 & 34,42 \\
\hline 4,5 & 24,18 & 34,53 \\
\hline 6,0 & 24,30 & 34,65 \\
\hline 7,5 & 24,52 & 34,78 \\
\hline 9,0 & 22,10 & 32,12 \\
\hline 10,5 & 21,89 & 31,75 \\
\hline
\end{tabular}

Fuente: Ahmad, Ahmad y Kashif [10]

De la mano de estos autores [8,10], Akinyele, Adekunle y Ogundaini [12] afirman que el $10 \%$ de reemplazo de cemento por hueso en polvo es una cifra ideal ya que en las pruebas realizadas a compresión en las probetas ya mencionadas, este porcentaje sobresale ante los demás, y supera la resistencia de la muestra de concreto puro (figura 4), y sustenta esta mayor resistencia en pruebas químicas realizadas, donde se evidencia que la ceniza del hueso pulverizado, tiene un porcentaje de óxido de calcio mayor que el cemento y clasificándola como puzolana $\mathrm{C}$, por tener un porcentaje de silicio por debajo del 70\% tal como lo tiene el cemento, según la ASTM C 618-94 (tabla 8).

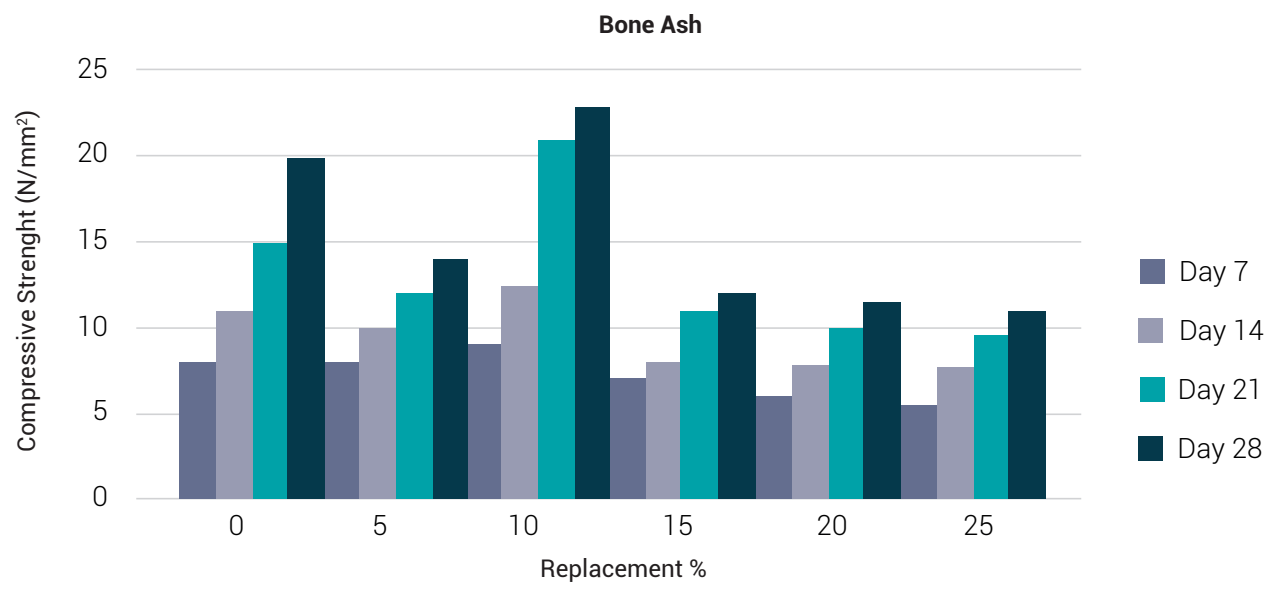

Figura 4. Resistencia a la compresión para la mezcla de cenizas de huesos

Fuente: Akinyele, Adekunle y Ogundaini [12] 
Tabla 8. Porcentaje de elementos de composición en muestras de prueba

\begin{tabular}{|c|c|c|c|}
\hline $\begin{array}{l}\text { Elementos } \\
\text { químicos }\end{array}$ & $\begin{array}{c}\text { Ceniza de polvo } \\
\text { de hueso }\end{array}$ & $\begin{array}{c}\text { Ceniza de polvo } \\
\text { de madera }\end{array}$ & Cemento \\
\hline $\mathrm{CuO}$ & 0,28 & - & - \\
\hline $\mathrm{SiO} 2$ & 2,28 & 48,96 & 20,7 \\
\hline $\mathrm{Al} 2 \mathrm{O} 3$ & 2,97 & 11 & 5,75 \\
\hline $\mathrm{Fe} 2 \mathrm{O} 3$ & 0,43 & 42 & 2,5 \\
\hline $\mathrm{CaO}$ & 76,31 & 0,6 & 64 \\
\hline $\mathrm{MgO}$ & 1,21 & 11,59 & 1,94 \\
\hline P2O5 & 5,57 & 5,05 & - \\
\hline $\mathrm{Na} 2 \mathrm{O}$ & 0,37 & - & - \\
\hline $\mathrm{K} 2 \mathrm{O}$ & 0,24 & - & - \\
\hline $\mathrm{MnO} 2$ & 0,086 & - & - \\
\hline $\mathrm{P} 4010$ & & - & - \\
\hline $\mathrm{SO} 3$ & - & - & 2,75 \\
\hline $\mathrm{CO} 3$ & & - & - \\
\hline LOI & 0,37 & 8,75 & 1,3 \\
\hline Ashing (g) & 0,32 & - & - \\
\hline Ash & 13,2 & & \\
\hline
\end{tabular}

Fuente: Akinyele, Adekunle y Ogundaini [12]

Contrario a lo dicho en "The Effect of Partial Replacement of Cement With Bone Ash and Wood Ash in Concrete" [12], los investigadores F.N.Okoye y O.I Odumodu [13], por medio de pruebas a compresión en especímenes cúbicos de $10 \mathrm{~cm}$, afirman que el polvo de hueso no es un material puzolánico ya que en el momento de sumergir las probetas con un reemplazo del $80 \%$ y $100 \%$ de cemento por este material, estas se deshicieron aproximadamente a las dos horas, lo que indica que el polvo de hueso no es un material adherente.

Tabla 9. Composición química del cemento y del polvo óseo

\begin{tabular}{ccc}
\hline Elementos químicos & Cemento Portland (\%) & Polvo de hueso (\%) \\
\hline Perdida de ignición & 0,98 & 3,29 \\
\hline $\mathrm{SiO} 2$ & 6 & 0,24 \\
\hline $\mathrm{CaO}$ & 68,7 & 53,2 \\
\hline $\mathrm{MgO}$ & 2,8 & 0,21 \\
\hline $\mathrm{P} 2 \mathrm{O} 5$ & - & 14,06 \\
\hline $\mathrm{Na} 2 \mathrm{O}$ & 1,36 & 1,36 \\
\hline $\mathrm{K} 2 \mathrm{O}$ & 0,5 & 0,2 \\
\hline
\end{tabular}




\begin{tabular}{ccc}
\hline Elementos químicos & Cemento Portland (\%) & Polvo de hueso (\%) \\
\hline $\mathrm{MnO} 2$ & 0,02 & 8,52 \\
\hline $\mathrm{Al} 2 \mathrm{O} 3$ & 0,29 & Rastro \\
\hline $\mathrm{Fe} 203$ & 0,03 & 0,008 \\
\hline
\end{tabular}

Fuente: Okoye y Odumodu [13]

También se hizo un estudio de compuestos químicos y sus diferencias con el cemento Portland, similares a las realizadas por Akinyele, Adekunle y Ogundaini [12] (tabla 8), en las que, si se hace una comparación entre la tabla 8 y la 9, se puede observar, que aunque son los mismos elementos químicos, las diferencias entre los componentes del hueso con respecto a los del concreto son pronunciadas. Esta carencia de propiedades del hueso con respecto al cemento Portland (tabla 9), es lo que permite que los autores de "Construction through the Use of Pulverized Bone Foamed Aerated Concrete (PB-FAC)" [13] adjudiquen la carencia de resistencia del concreto con diferentes porcentajes de hueso pulverizado y de la misma manera que los investigadores $[7,10,12]$ es notorio que amayor porcentaje de este material, menor resistencia a la compresión (figura 5).

30

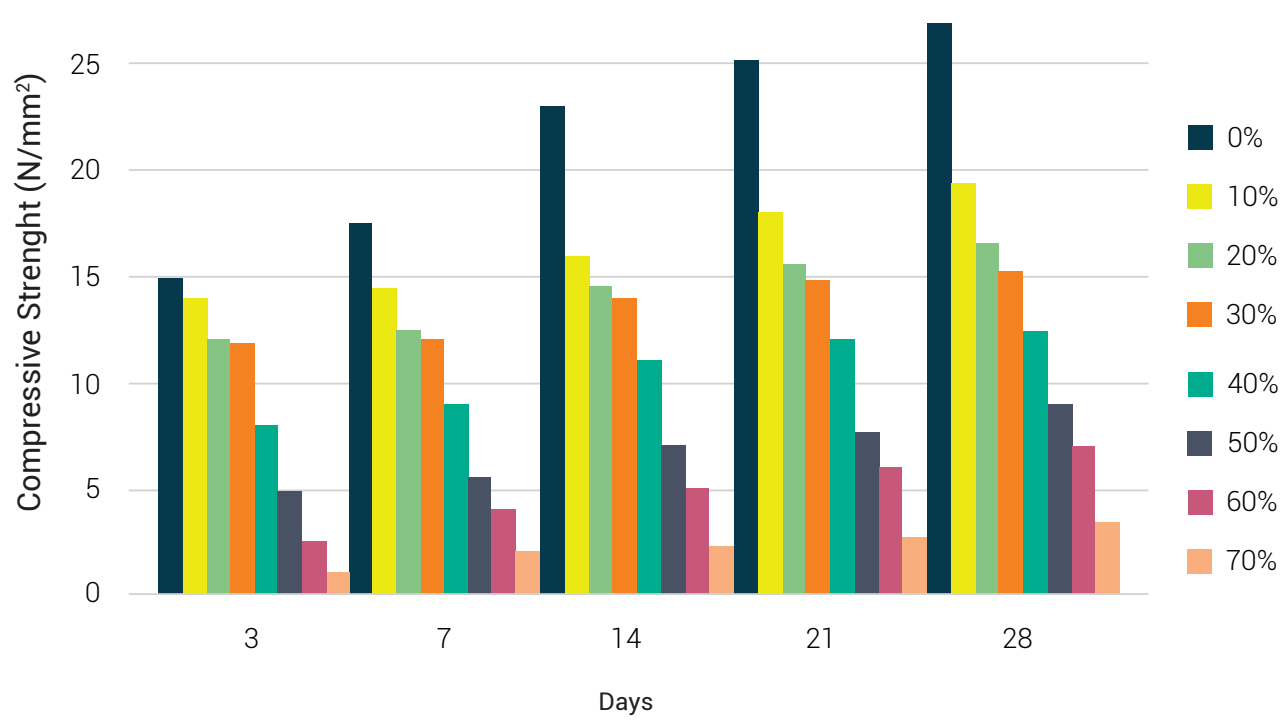

Figura 5. Resistencia a la compresión del hormigón con diversas proporciones de polvo óseo

Fuente: Okoye y Odumodu [13] 
A pesar de que los resultados no son satisfactorios para estos autores [13], aseguran que el 10\% de reemplazo de cemento por polvo de hueso es una cifra ideal para ejercer cualquier labor y que los tiempos de fraguado se elevan notoriamente, lo que permite que se reduzcan las fisuraciones por retracción al fraguado.

Otro investigador que arrojó resultados favorables fue Navya [14], quien con la metodología utilizada por Akinyele, Adekunle y Ogundaini [12], realizó pruebas a compresión a los 7 y 28 días de hidratación, reemplazando en 3 porcentajes diferentes el cemento por cascarilla de arroz calcinada ( $\mathrm{RHA}$ ) y en otros 3 porcentajes el agregado grueso, por huesos de cabra y oveja (CCB) también se hizo un séptimo reemplazo donde se conjugaron ambos agregados alternativos en un 10\% de cada uno (tabla 10).

Tabla 10. Designaciones de cenizas de cáscara de arroz y huesos de ganado triturado

\begin{tabular}{ccc}
\hline & \% de reemplazo & Nombre \\
\hline 1 & $0 \%$ & $\mathrm{~N}$ \\
\hline 2 & $5 \% \mathrm{RHA}$ & $\mathrm{N} 1$ \\
\hline 3 & $10 \% \mathrm{RHA}$ & $\mathrm{N} 2$ \\
\hline 4 & $15 \% \mathrm{RHA}$ & $\mathrm{N} 3$ \\
\hline 5 & $10 \% \mathrm{CCB}$ & $\mathrm{N} 4$ \\
\hline 6 & $20 \% \mathrm{CCB}$ & $\mathrm{N} 5$ \\
\hline 7 & $30 \% \mathrm{CCB}$ & $\mathrm{N} 6$ \\
\hline 8 & $10 \% \mathrm{RHA} 10 \% \mathrm{CCB}$ & $\mathrm{N} 7$ \\
\hline
\end{tabular}

Fuente: Navya [14]

Los resultados a compresión fueron favorables en RHA como en CCB, solo hasta el 10\%, ya que, al superar este porcentaje, las mezclas empezaron a disminuir su resistencia a la compresión, aunque todos los porcentajes superaron la resistencia con la mezcla al 0\%. La mezcla N7 que conjuga ambos reemplazos en 10\% supera la mezcla pura por más de 3Mpa, dando un referente más de idoneidad en reemplazos al $10 \%$ ya no solo utilizando el hueso sino también otros elementos alternativos (tabla 11).

Tabla 11. Resistencia a la compresión durante 7 y 28 días

\begin{tabular}{lcccccccc}
\hline & N & N1 & N2 & N3 & N4 & N5 & N6 & N7 \\
\hline Resistencia a la compresión a los 7 días & 28,44 & 31,55 & 33,14 & 30,01 & 32,36 & 31,07 & 30,51 & 34,10 \\
\hline Resistencia a la compresión a los 28 días & 42,25 & 43,81 & 45,02 & 41,95 & 45,55 & 44,35 & 43,27 & 45,40 \\
\hline
\end{tabular}

Fuente: Navya [14]

Ingeniería Solidaria 
La tracción fue medida con probetas cilíndricas que cuentan con un dimensionamiento de $15 \mathrm{~cm}$ de diámetro por una altura de $30 \mathrm{~cm}$, donde el comportamiento porcentual de los agregados alternativos fue igual que el de las pruebas a compresión resaltando la muestra N7 con la conjugación de los agregados alternativos que supera la mezcla pura por 0,56Mpa (tabla 12).

Tabla 12. Resistencia a la tracción durante 7 y 28 días

\begin{tabular}{lcccccccc}
\hline & N & N1 & N2 & N3 & N4 & N5 & N6 & N7 \\
\hline Resistencia a la tracción a los 7 días & 3,12 & 3,66 & 3,94 & 3,49 & 3,78 & 3,56 & 3,62 & 4,03 \\
\hline Resistencia a la tracción a los 28 días & 4,06 & 4,32 & 4,48 & 4,25 & 4,53 & 4,35 & 4,08 & 4,62 \\
\hline
\end{tabular}

Fuente: Navya [14]

No ajeno al comportamiento porcentual de las pruebas a compresión y tracción, las pruebas a flexión reaccionaron porcentualmente igual, lo que dio un resultado de conjugación de materiales 1,14Mpa por encima de la mezcla pura (tabla 13) en probetas con una longitud de $50 \mathrm{~cm}$, por una sección trasversal de $10 \mathrm{~cm} \times 10 \mathrm{~cm}$.

Tabla 13. Resistencia a la flexión durante 7 y 28 días

\begin{tabular}{ccccccccc}
\hline & N & N1 & N2 & N3 & N4 & N5 & N6 & N7 \\
\hline Resistencia a la flexión a los 7 días & 6,05 & 6,54 & 6,71 & 6,37 & 6,83 & 6,69 & 6,45 & 7,12 \\
\hline Resistencia a la flexión a los 28 días & 6,94 & 7,53 & 7,62 & 7,36 & 7,70 & 7,50 & 7,42 & 8,08 \\
\hline
\end{tabular}

Fuente: Navya [14]

No todos los resultados son tan favorables como los mencionados, sin embargo con todas las resistencias por debajo de la prueba del $0 \%$, como se puede observar en la tabla 14, Falade, Ikponmwosa y Fapohunda [13] encontraron en el reemplazo del cemento al 20\% por hueso pulverizado un ahorro de 29,61\% que fue puesto en práctica sobre un estudio de vivienda de interés social para Nigeria poniendo aparte de la resistencia a la tracción y compresión otros aspectos como trabajabilidad, densidad y capacidad de absorción. 
Tabla 14. Características del hormigón celular a una densidad de diseño de $1600 \mathrm{~kg} / \mathrm{m} 3$

\begin{tabular}{lccccc}
\hline & 0\%PB & $\mathbf{5 \% P B}$ & $\mathbf{1 0 \% P B}$ & $\mathbf{1 5 \% P B}$ & $\mathbf{2 0 \% P B}$ \\
\hline Densidad húmeda $(\mathrm{kg} / \mathrm{m3})$ & 1668,28 & 1627,19 & 1603,71 & 1589,69 & 1563,68 \\
\hline $\begin{array}{l}\text { Densidad seca }(\mathrm{kg} / \mathrm{m} 3) \\
\quad \text { Curado al aire }\end{array}$ & 1662,50 & 1659,23 & 1648,29 & 1623,78 & 1603,24 \\
$\quad$ Curado en agua & 1689,29 & 1679,01 & 1648,29 & 1631,89 & 1621,79 \\
\hline Densidad de prueba (kg/m3) & & & & & \\
$\quad$ Curado al aire & 1662,50 & 1659,23 & 1648,29 & 1623,78 & 1603,24 \\
$\quad$ Curado en agua & 1689,29 & 1679,01 & 1648,29 & 1631,89 & 1621,79 \\
\hline Resistencia a la compresión (N/mm2) & & & & & 12,98 \\
$\quad$ Curado al aire & 15,43 & 14,23 & 14,01 & 13,26 & 11,34 \\
$\quad$ Curado en agua & 13,89 & 13,24 & 12,81 & 12,11 & \\
\hline Resistencia a la tracción (N/mm2) & & & & & \\
$\quad$ Módulo de ruptura & 2,53 & 2,53 & 2,11 & 2,11 & \\
$\quad$ Splitting Test & 1,63 & 1,56 & 1,56 & 0,99 & 0,85 \\
\hline
\end{tabular}

Fuente: Falade, Ikponmwosa y Fapohunda [13]

Los resultados por debajo de la resistencia de la muestra de concreto puro fueron corroborados por Ogarekpe et al. [11], quienes por medio de la calcinación de huesos de vaca a $92^{\circ} \mathrm{C}$ reemplazaron el agregado fino y obtuvieron resultados no satisfactorios en cuanto a resistencia y economía, ya que el hueso de vaca actúa como un retardante en los tiempos de fraguado, lo que confirma lo dicho por Okoye y Odumodu [13], e implica que haya un aumento en la proporción agua y cemento a medida que aumenta el porcentaje de hueso y de la misma manera que anteriores investigadores [7], [8], [10], [12], [13], a mayor cantidad de hueso, menor resistencia a la compresión como se muestra en la figura 6.

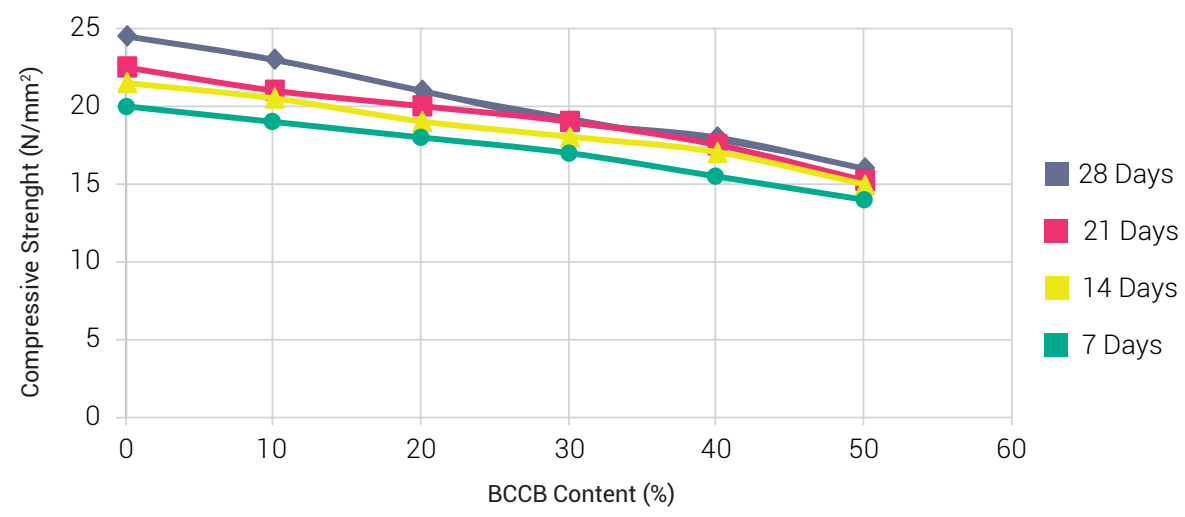

Figura 6. Resistencia a la compresión del hormigón con BCCB como parcial reemplazo para agregado fino

Fuente: Ogarekpe et al. [11] 
A diferencia de [11], otros autores que utilizaron el hueso calcinado a más de $900^{\circ} \mathrm{C}[17]$ mostraron que la sustitución de hueso calcinado genera una mayor resistencia a la compresión (tabla 15), pero no aclaran otros factor es en cuanto a porcentaje de reemplazo, tiempos de calcinación y de curado, lo que deja una serie de dudas, con respecto a la economía.

Tabla 15. Resistencia a la compresión en cilindros

\begin{tabular}{ccccccc}
\hline $\begin{array}{c}\text { Cilindro } \\
\text { No. }\end{array}$ & Localización & $\begin{array}{c}\text { Días de } \\
\text { curado }\end{array}$ & $\begin{array}{c}\text { Peso } \\
\mathbf{( K g )}\end{array}$ & $\begin{array}{c}\text { Carga } \\
\text { máxima (KN) }\end{array}$ & $\begin{array}{c}\text { Resistencia } \\
\mathbf{( K g / \mathbf { }})\end{array}$ & $\begin{array}{c}\text { \% de } \\
\text { desarrollo }\end{array}$ \\
\hline N1 & Concreto & 7 & 3500 & 128 & 166,18 & 79 \\
\hline N2 & Concreto & 14 & 3400 & 136,8 & 177,61 & 85 \\
\hline N3 & Concreto & 21 & 3560 & 162,9 & 211,5 & 101 \\
\hline P1 & $\begin{array}{c}\text { Concreto más } \\
\text { hueso calcinado }\end{array}$ & 7 & 3500 & 142,1 & 184,47 & 88 \\
\hline P2 & $\begin{array}{c}\text { Concreto más } \\
\text { hueso calcinado }\end{array}$ & 14 & 3400 & 150,5 & 195,37 & 93 \\
\hline P3 & $\begin{array}{c}\text { Concreto más } \\
\text { hueso calcinado }\end{array}$ & 21 & 3560 & 180,8 & 234,76 & 112 \\
\hline
\end{tabular}

Fuente: Monroy et al. [17]

Junto a Monroy et al. [17], los reemplazos de cemento por hueso calcinado, también muestran un excelente desempeño en [9], quienes ilustran en la figura 7, que el cemento reemplazado hasta un 10\% por hueso calcinado, genera una mayor resistencia a la compresión, pero que al superar este porcentaje, la mezcla puede perder resistencia y si es elevada al $20 \%$ su resistencia es inferior a la mezcla pura.

Aunque [9] no muestran mayor detalle en los resultados, procedimiento, temperaturas y tiempos de calcinación, si aseguran que este material es un elemento trabajable dentro de la construcción generador de ahorro y beneficios técnicos como los aumentos y reducción en los tiempos de fraguado. 


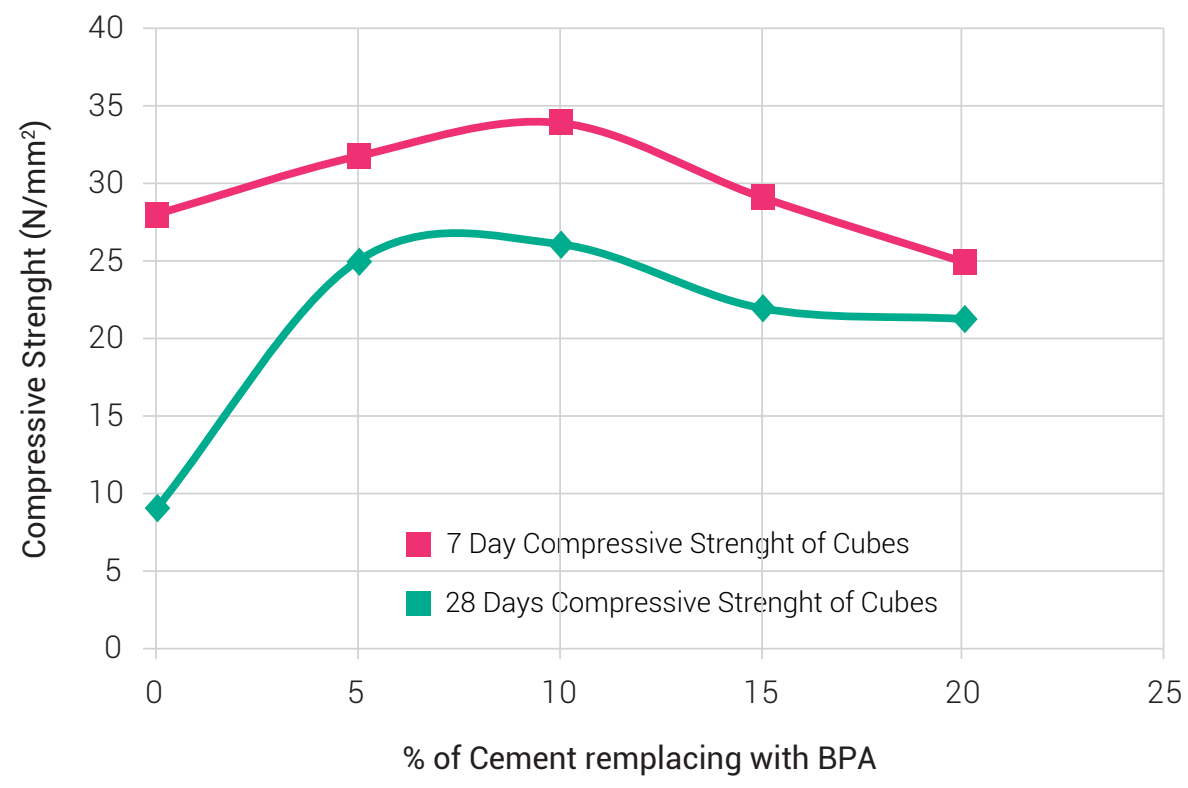

Figura 7. Comparación de la resistencia a la compresión durante 7 y 28 días

Fuente: Varma et al. [9]

\section{Metodología}

Al comparar las propiedades mecánicas del hueso humano con el gráfico típico de esfuerzo deformación (figura 8) y con las propiedades del concreto y el acero utilizado para el concreto reforzado (figuras 9 y 10), se puede observar que los valores máximos de resistencia a la compresión tanto en las pruebas hechas por el ingeniero Álvaro Mendoza [3], como las hechas al hueso cortical [1], se encuentran por encima del concreto de mayor resistencia que es de 35,2 MPa, donde el mínimo valor es de 107.5MPa y el máximo es de $213 \mathrm{MPa}$. En las pruebas realizadas a tracción siendo el menor valor 76,6 MPa y el mayor $170 \mathrm{MPa}$ ambos se encuentran por debajo de la resistencia mínima del acero de refuerzo [5], pero aun así siguen estando por encima de la resistencia a compresión del concreto, la cual es prácticamente 0 , ya que por retracción al fraguado el concreto tiende a fallar. 


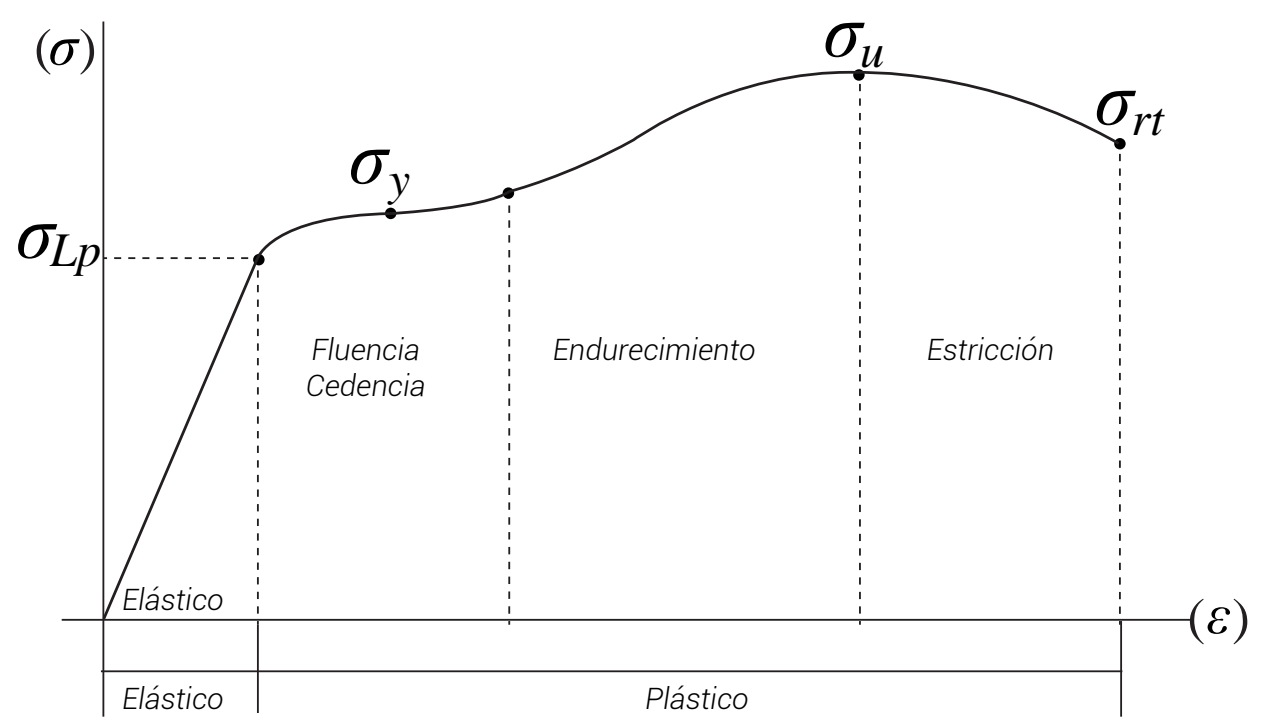

Figura 8. Diagrama esfuerzo deformación

Fuente: Mora [5]

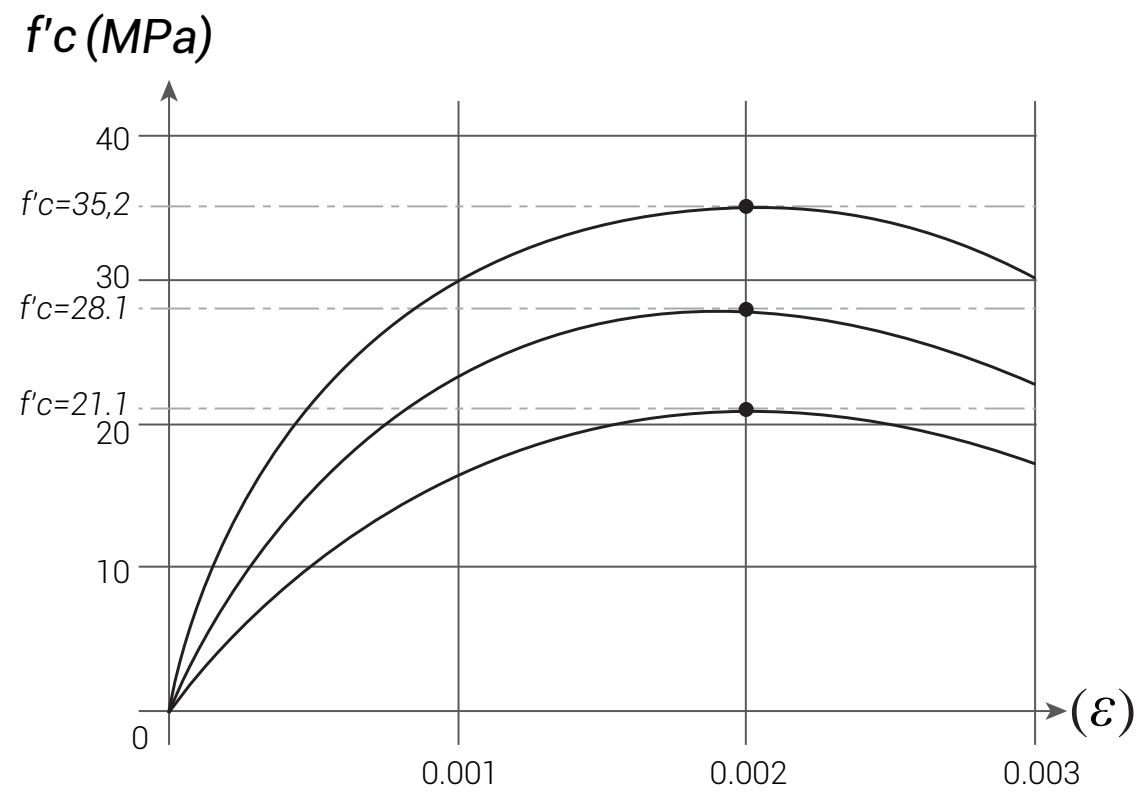

Figura 9. Tipos de concreto a compresión, diagrama esfuerzo deformación

Fuente: Mora [5] 


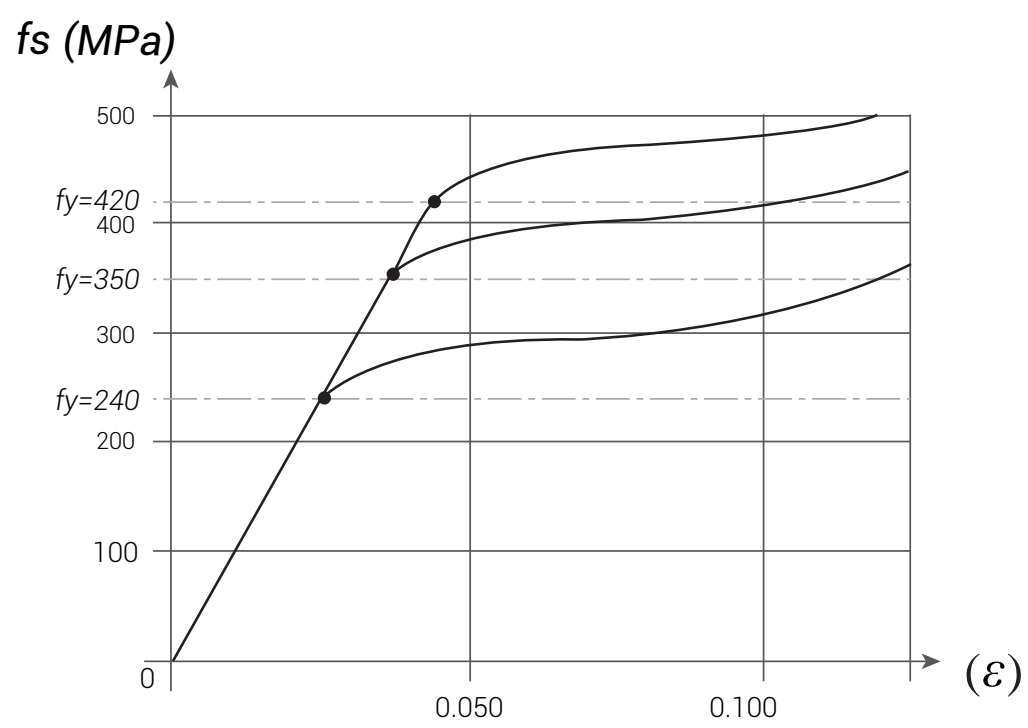

Figura 10. Tipos de acero a tracción, diagrama esfuerzo deformación

Fuente: Mora [5]

Viendo el satisfactorio comportamiento mecánico del hueso humano, hay una alta posibilidad de que el tejido óseo de la res pueda llegar a arrojar los mismos o mejores resultados, ya que sus compuestos orgánicos e inorgánicos son los mismos, lo que permite deducir que se puede hacer del hueso de res un componente más dentro de la mezcla para el concreto. No se debe pasar por alto que estas pruebas directas sobre el hueso fueron hechas sobre un elemento óseo fresco, donde gran parte del contenido orgánico todavía se encontraba activo, elemento al que algunos investigadores le adjudican la debilidad dentro de la mezcla y en el momento que este elemento sea eliminado, se busca que el hueso genere una mayor resistencia.

\subsection{Introducción del tejido óseo de la res en el concreto}

La mejor forma de introducir el tejido óseo dentro del concreto es buscando que cumpla con la definición que se da a alguno de los componentes de la mezcla. El primer logro se obtuvo por medio de la incineración, la cual convirtió el hueso en un material puzolánico, que se define como un elemento, que después de ser humedecido y secado a temperatura ambiente, toma un nivel de fraguado y endurecimiento. Somma y Rochinotti [18] afırman que "la ceniza de huesos se obtiene al quemar restos óseos de distintos orígenes a una temperatura superior a $600^{\circ} \mathrm{C}$ durante un período mayor de una hora, debiéndose constatar la ausencia de proteínas"; pero para eliminar todo 
componente orgánico, el hueso debe ser calcinado a una temperatura de $1200^{\circ} \mathrm{C}$ [19], por eso, en busca de un punto medio entre estas dos temperaturas se decide tomar $900^{\circ} \mathrm{C}$ como una opción más y se procede a realizar la calcinación en diferentes tiempos a diferentes temperaturas.

El proceso de calcinación por un tiempo de dos horas a $600^{\circ} \mathrm{C}, 900^{\circ} \mathrm{C}$ y $1200^{\circ} \mathrm{C}$, da como resultado una ceniza con diferentes características, la cual a $600^{\circ} \mathrm{C}$ presentó partículas de color gris oscuro con una granulometría variada (figura 11); a los $900^{\circ} \mathrm{C}$, la ceniza disminuyó su granulometría con una tonalidad gris más clara; y a los $1200^{\circ} \mathrm{C}$, se mostró una granulometría fina con una tonalidad blanca muy similar a la harina de trigo (figura 12). Los tiempos de incineración a 1 y 2 horas no tuvieron ninguna influencia en cuanto a tonalidad y cambio de granulometría.

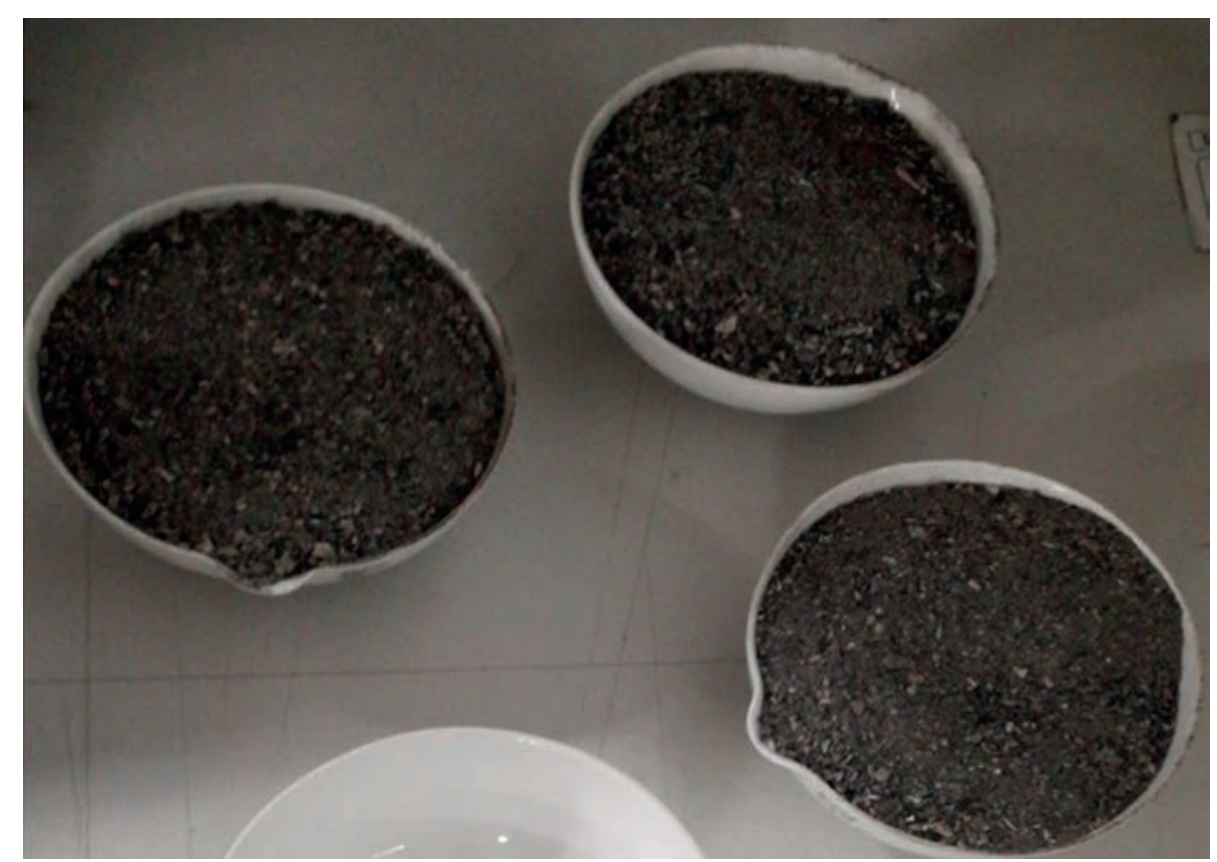

Figura 11. Ceniza de hueso calcinada a $900^{\circ} \mathrm{C}$

Fuente: Pedraza et al. [20] 


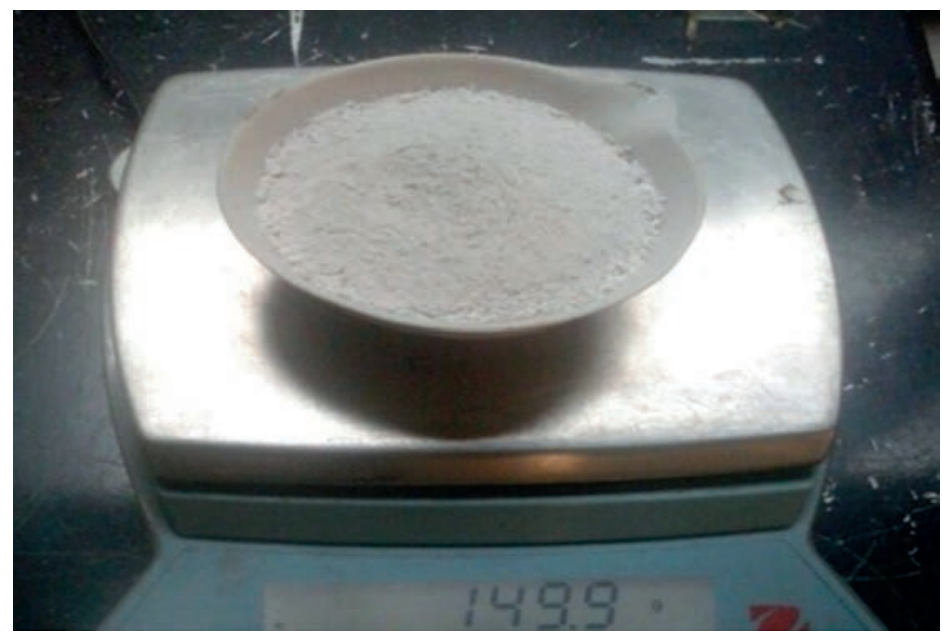

Figura 12. Ceniza de hueso calcinada a $1200^{\circ} \mathrm{C}$

Fuente: Pedraza et al. [20]

La materia orgánica con que cuenta el hueso después de ser calcinado a cada una de las temperaturas es medida mediante la tonalidad final, que es comparada con el color de referencia que ofrece la placa orgánica de colores según la norma INV E-212-07 [21] (figura 13), donde a pesar de que a los $600^{\circ} \mathrm{C}$ y $900^{\circ} \mathrm{C}$ no se mostró una ausencia total de materia orgánica, las tonalidades generadas no fueron muy significativas, lo que permitió que las tres temperaturas fueran utilizadas dentro de los especímenes de pasta de cemento.

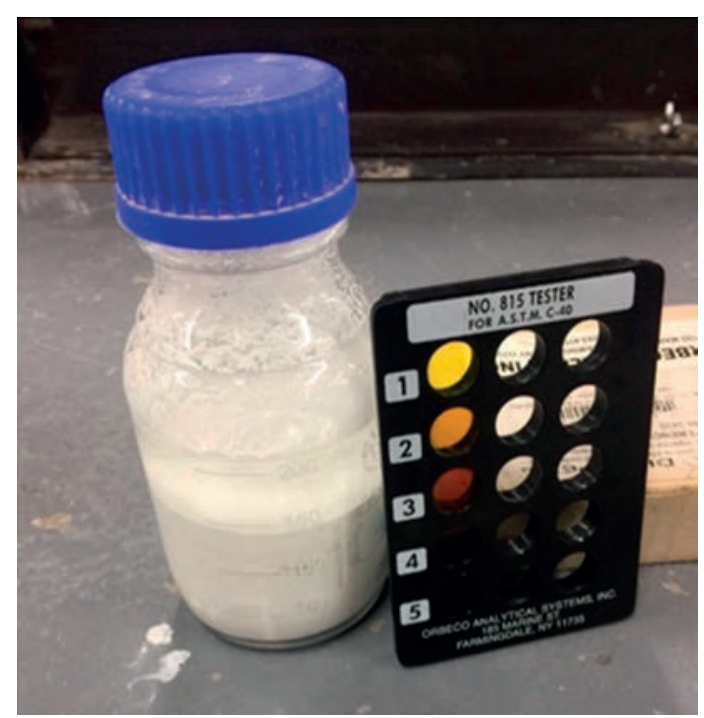

Figura 13. Placa orgánica de Colores

Fuente: Pedraza et al. [20] 
Mediante una inspección visual, se puede percibir que el hueso calcinado a $1200^{\circ} \mathrm{C}$ presenta una caracterización muy similar a la del cemento puro y al ponerlo dentro del tamiz número 200 fluye más del 80\% del material. La similitud de este elemento con la del cemento permite decidir que le sean realizadas al hueso de $1200^{\circ} \mathrm{C}$ las mismas pruebas de laboratorio que se le realizan al cemento y a la pasta de cemento, para saber si este es apto para incluirlo dentro de la mezcla reemplazando un porcentaje determinado de material cementante.

La primera prueba realizada al hueso incinerado a $1200^{\circ} \mathrm{C}$ fue hecha por medio del aparato de Blaine de permeabilidad del aire, según la norma INV E-302-07 [22], con el que se busca determinar la finura del cemento por medio del cálculo de la superficie específica (S), observando un valor inferior al del cemento, haciéndolo apto para ser incluido dentro de la mezcla.

Hueso Calcinado: $S=3944 \frac{\mathrm{cm}^{2}}{\mathrm{gr}}$

Cemento: $S=4604 \frac{\mathrm{cm}^{2}}{\mathrm{gr}}$

La medición de densidad del hueso calcinado fue la segunda prueba realizada mediante la norma INV E-307-07 [22], la cual se fundamenta en el vertimiento de kerosene en el frasco de chatelier máximo a $7 \mathrm{ml}$. Posteriormente, se agrega $64 \mathrm{gr}$ del material cementante, que para este caso será reemplazado por materia ósea calcinada, desplazando el líquido a un nivel superior, marcando un volumen de $21.4 \mathrm{~cm}^{3}$.

$$
\begin{aligned}
& \text { Densidad }=\frac{\text { Masa Cemento }}{\text { Volumen Desplazado }} \\
& \text { Densidad }=\frac{64 \mathrm{gr}}{21.4 \mathrm{~cm}^{3}}=2.99 \frac{\mathrm{gr}}{\mathrm{cm}^{3}}
\end{aligned}
$$

Este procedimiento fue desarrollado de la misma manera con el cemento a utilizar, el cual arrojó los mismos resultados entregando una densidad del hueso calcinado igual a la del cemento.

Con los resultados favorables de finura y densidad arrojados por el hueso calcinado, se procede a hacer un reemplazo del 10\% de material cementante para medir la consistencia de la pasta de cemento por medio de la aguja de Vicat en tres muestras diferentes (tabla 16). 
Tabla 16. Consistencia de pasta de cemento con un 10\% reemplazado por hueso calcinado

\begin{tabular}{ccccc}
\hline Ensayo & $\begin{array}{c}\text { Peso de la muestra } \\
(\mathbf{g r})\end{array}$ & $\begin{array}{c}\text { Cantidad de agua } \\
(\mathbf{m l})\end{array}$ & $\begin{array}{c}\text { Penetración } \\
(\mathbf{m m})\end{array}$ & \% de agua \\
\hline 1 & 650 & 170 & 8 & 26,15 \\
\hline 2 & 650 & 175 & 8.5 & 26,92 \\
\hline 3 & 650 & 180 & 9 & 27,69 \\
\hline
\end{tabular}

Fuente: Pedraza et al. [20]

$\%$ de Agua Requerida $=\frac{\text { Cantidad de Agua }}{\text { Peso Muestra }} * 100$

$\%$ de Agua Requerida $=\frac{180 \mathrm{ml}}{650 \mathrm{gr}} * 100=27.69 \%$ de agua

La tabla 17 es el resultado de la prueba de consistencia sobre las tres muestras de cemento sin ninguna clase de reemplazo parcial.

Tabla 17. Consistencia de pasta de cemento

\begin{tabular}{ccccc}
\hline Ensayo & $\begin{array}{c}\text { Peso de la } \\
\text { muestra (gr) }\end{array}$ & $\begin{array}{c}\text { Cantidad de agua } \\
(\mathbf{m l})\end{array}$ & $\begin{array}{c}\text { Penetración } \\
(\mathbf{m m})\end{array}$ & \% de agua \\
\hline 1 & 650 & 180 & 7 & 27,69 \\
\hline 2 & 650 & 195 & 8.5 & 30,00 \\
\hline 3 & 650 & 200 & 9 & 30,77 \\
\hline
\end{tabular}

Fuente: Pedraza et al. [20]

$\%$ de Agua Requerida $=\frac{200 \mathrm{ml}}{650 \mathrm{gr}} * 100=30.77 \%$ de agua

Al comparar los resultados de las tablas 16 y 17, se observa que la pasta de cemento con $10 \%$ de hueso calcinado presenta una ventaja sobre las muestras con cemento puro, ya que esta requiere un $3,08 \%$ menos de agua.

La segunda prueba por realizar sobre la pasta de cemento pura y con 10\% de hueso bobino calcinado, también es hecha por medio de la aguja de Vicat siguiendo las indicaciones de la norma INV E-305-07 [23]. 
Tejido óseo, una nueva alternativa en agregados para el concreto

Tabla 18. Tiempos de fraguado para pasta de cemento con $10 \%$ de hueso calcinado

\begin{tabular}{cccc}
\hline Ensayo & Tiempo (min) & Penetración (mm) & Tiempo (h) \\
\hline 1 & 30 & 41 & 0,50 \\
\hline 2 & 45 & 41 & 0,75 \\
\hline 3 & 60 & 41 & 1,00 \\
\hline 4 & 75 & 41 & 1,25 \\
\hline 5 & 90 & 41 & 1,50 \\
\hline 6 & 105 & 41 & 1,75 \\
\hline 7 & 120 & 40 & 2,00 \\
\hline 8 & 135 & 40 & 2,25 \\
\hline 9 & 150 & 40 & 2,50 \\
\hline 10 & 165 & 38 & 2,75 \\
\hline 11 & 180 & 36 & 3,00 \\
\hline 12 & 195 & 23 & 3,25 \\
\hline 13 & 210 & 7 & 3,50 \\
\hline 14 & 225 & 3 & 3,75 \\
\hline 15 & 240 & 0 & 4,00 \\
\hline
\end{tabular}

Fuente: Pedraza et al. [20]

Tiempo de fraguado

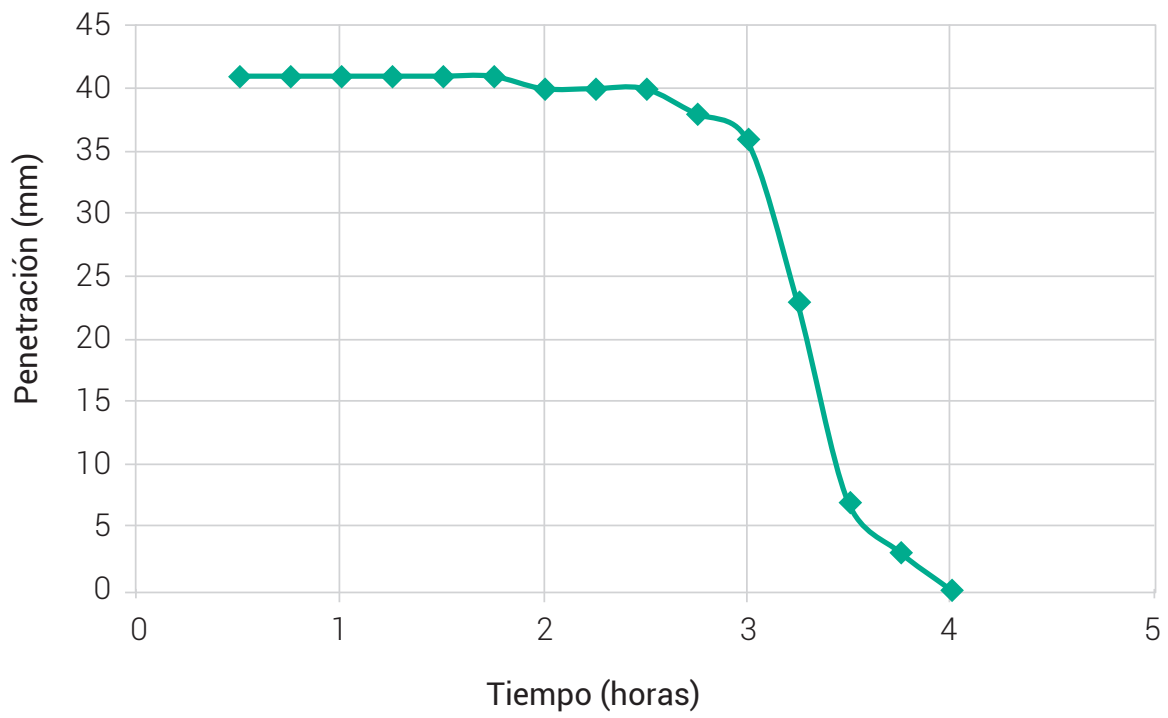

Figura 14. Tiempos de fraguado para pasta de cemento con $10 \%$ de hueso calcinado

Fuente: Pedraza et al. [20]

La tabla 19 muestra los tiempos de fraguado de la pasta de cemento pura. 
Tabla 19. Tiempos de fraguado para pasta de cemento

\begin{tabular}{|c|c|c|c|}
\hline Ensayo & Tiempo (min) & Penetración (mm) & Tiempo (h) \\
\hline 1 & 30 & 42 & 0,50 \\
\hline 2 & 45 & 42 & 0,75 \\
\hline 3 & 60 & 41 & 1,00 \\
\hline 4 & 75 & 41 & 1,25 \\
\hline 5 & 90 & 41 & 1,50 \\
\hline 6 & 105 & 41 & 1,75 \\
\hline 7 & 120 & 41 & 2,00 \\
\hline 8 & 135 & 41 & 2,25 \\
\hline 9 & 150 & 41 & 2,50 \\
\hline 10 & 165 & 41 & 2,75 \\
\hline 11 & 180 & 41 & 3,00 \\
\hline 12 & 195 & 41 & 3,25 \\
\hline 13 & 210 & 39 & 3,50 \\
\hline 14 & 225 & 27 & 3,75 \\
\hline 15 & 240 & 25 & 4,00 \\
\hline 16 & 255 & 10 & 4,25 \\
\hline 17 & 270 & 2 & 4,50 \\
\hline 18 & 285 & 0 & 4,75 \\
\hline
\end{tabular}

Fuente: Pedraza et al. [20]

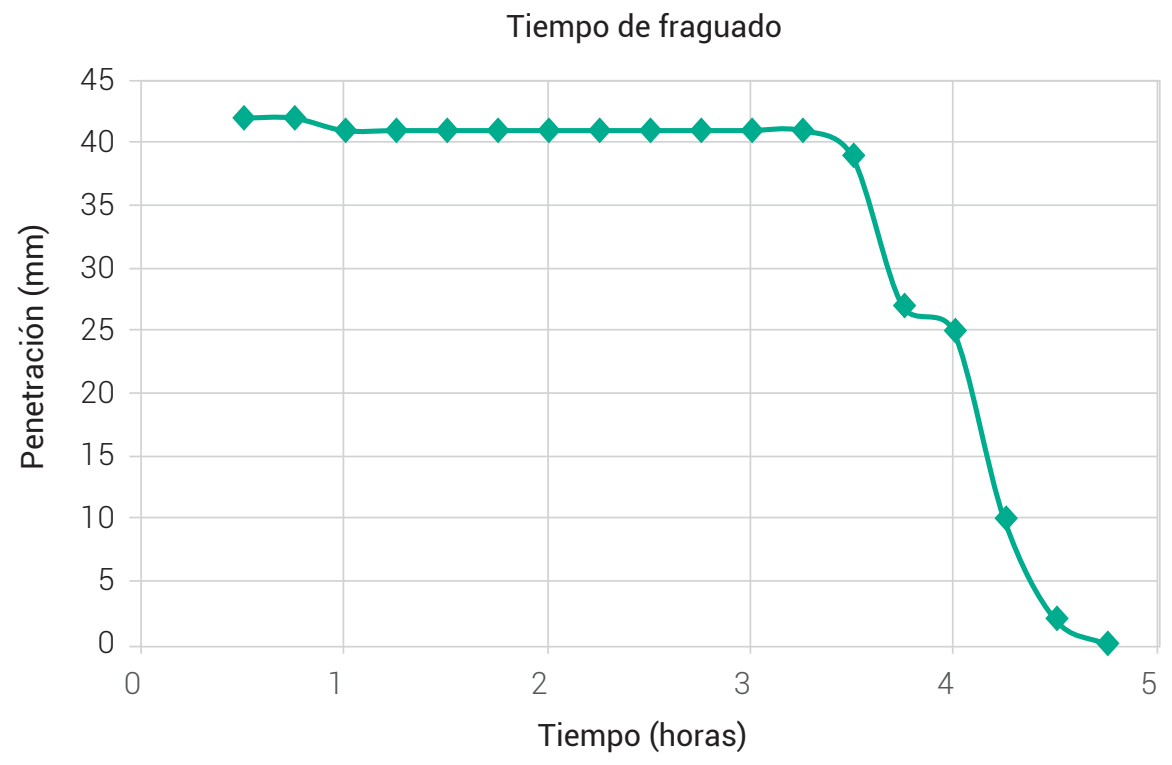

Figura 15. Tiempos de fraguado para pasta de cemento

Fuente: Pedraza et al. [20] 
Al comparar las figuras 14 y 15, se observa que los tiempos de fraguado de la pasta de cemento con 10\% de hueso calcinado, se reducen en 45 minutos.

La notoria y favorable diferencia que arroja el hueso calcinado al incluirlo dentro de la pasta de cemento, abre un nuevo espacio para realizar pruebas a compresión sobre la misma pasta con reemplazos parciales de 10, 15 y 20\%, variando las temperaturas de calcinación en tres rangos de 600,900 y $1200^{\circ} \mathrm{C}$ por tiempos de 1 y 2 horas, bajo la norma INV E-323-07 [24] con cubos de 50mm de lado como se muestra en la figura 16.

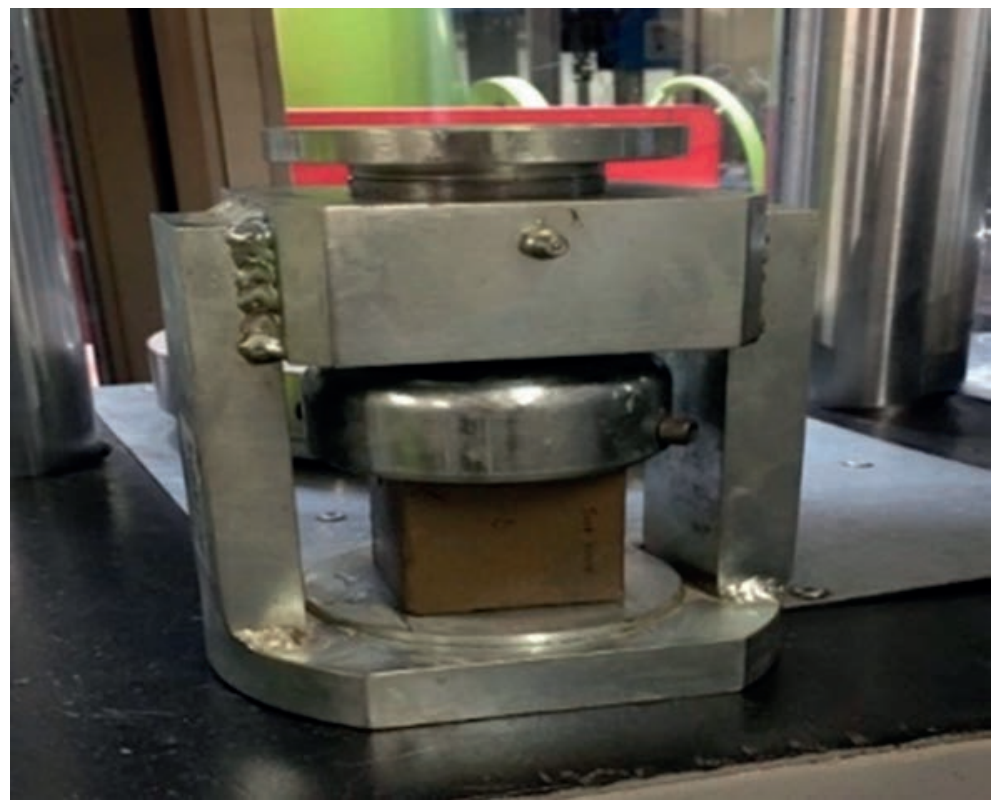

Figura 16. Resistencia a la Compresión en cubos de pasta de cemento

Fuente: Pedraza et al. [20]

Las pruebas a compresión sobre la pasta de cemento pura (tabla 20, figura 17) evidencian el incremento de resistencia con respecto a los días de hidratación; estas muestras también son un referente comparativo para medir la resistencia en las muestras con adición de hueso calcinado. 
Tabla 20. Prueba a compresión pasta de cemento convencional

\begin{tabular}{cccc}
\hline \multirow{4}{*}{ Comento + agua } & \\
\hline \multirow{3}{*}{ Convencional } & Masa $[\mathrm{g}]$ & Días & Resistencia $\left[\mathrm{kg} / \mathrm{cm}^{2}\right]$ \\
\cline { 2 - 4 } & 244,6 & 7 & 104,8 \\
\cline { 2 - 4 } & 245,1 & 14 & 138,3 \\
\cline { 2 - 4 } & 245,8 & 28 & 182,4 \\
\hline
\end{tabular}

Fuente: Pedraza et al. [20]

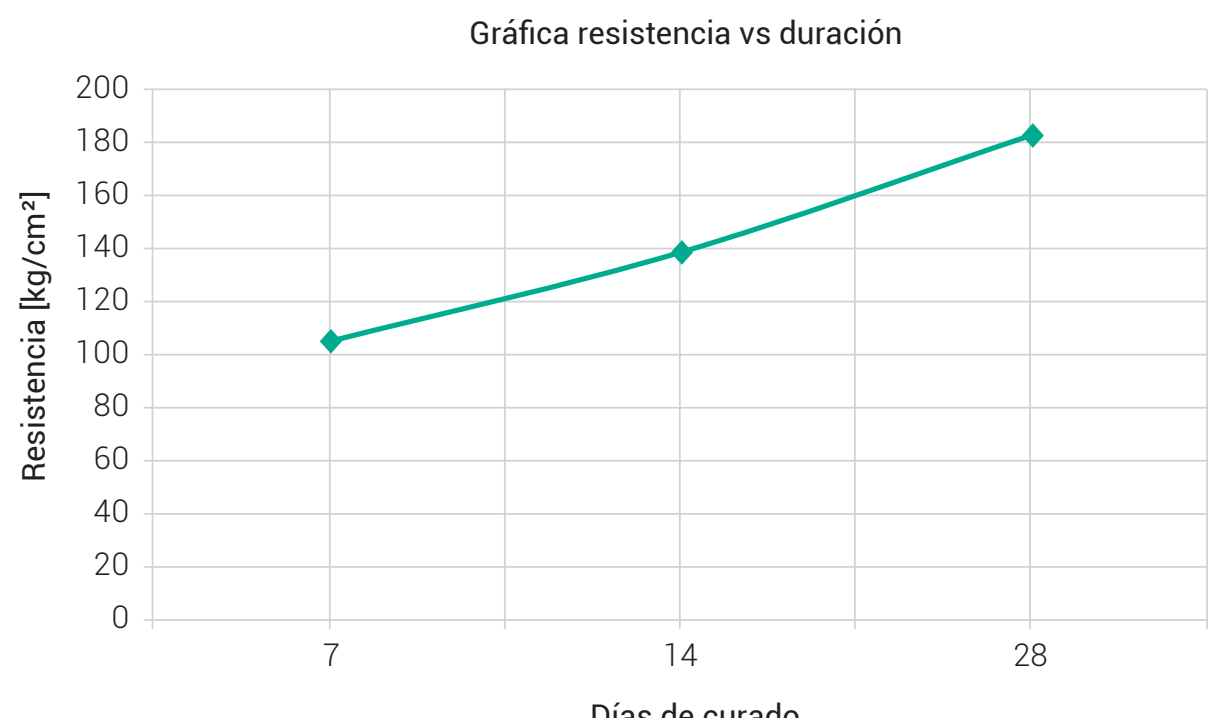

Figura 17. Prueba a compresión pasta de cemento convencional

Fuente: Pedraza et al. [20]

\section{Resultados}

Las tablas 21, 22 y 23 presentan los resultados arrojados por cada muestra fallada a compresión, e indican su respectivo porcentaje de hueso bovino incluido con temperaturas días de hidratación y demás especificaciones.

Las pruebas a compresión realizadas en especímenes con un 10\% de hueso calcinado reflejan sus resultados en la tabla 21 y en la figura 18; lo que evidencia una mayor resistencia de las muestras con hueso a $1200^{\circ} \mathrm{C}$ incinerado por una hora, que llegan a superar la resistencia de la pasta pura en los tres tiempos, donde se hace notorio que a mayor tiempo de hidratación, es menor la diferencia de resistencia entre 
los dos tipos de pasta. Cabe resaltar que la muestra con hueso calcinado a $600^{\circ} \mathrm{C}$ por 2 horas aunque no alcanza la misma resistencia que la pasta pura, su diferencia con esta es mínima y constante.

En la tabla 22 y en la figura 19 los resultados ilustrados son producto del reemplazo del cemento puro en un $15 \%$ por hueso calcinado, donde se evidencia que el hueso tratado a los $1200^{\circ} \mathrm{C}$ por una hora presenta una mayor resistencia que la pasta de cemento convencional a los 7 y los 14 días de hidratación, pero a los 28 días su resistencia disminuye de una manera drástica. Las demás pruebas, muestran una resistencia menor, y la más cercana a la muestra piloto es la que cuenta con hueso calcinado a $600^{\circ} \mathrm{C}$ por una hora.

El reemplazo del 20\% de cemento por hueso calcinado en la tabla 23 y en la figura 20 entrega los resultados donde la prueba realizada a los 7 días en la pasta de cemento con hueso calcinado a $600^{\circ} \mathrm{C}$ por una hora, a $900^{\circ} \mathrm{C}$ por una y dos horas presentan mayor resistencia que la pasta de cemento convencional. Los demás resultados de este porcentaje son demasiado dispersos y no muestran un comportamiento favorable y estandarizado.

Tabla 21. Prueba a compresión en pasta de cemento con $10 \%$ de hueso calcinado

\begin{tabular}{|c|c|c|c|c|c|c|c|}
\hline \multirow{3}{*}{ Muestra } & \multirow{3}{*}{$\begin{array}{l}\text { Área } \\
\mathbf{m m}^{2}\end{array}$} & \multicolumn{6}{|c|}{ Resistencia a la compresión } \\
\hline & & \multicolumn{2}{|c|}{7 días } & \multicolumn{2}{|c|}{14 días } & \multicolumn{2}{|c|}{28 días } \\
\hline & & $\mathrm{kg} / \mathrm{cm}^{2}$ & Mpa & $\mathrm{kg} / \mathrm{cm}^{2}$ & Mpa & $\mathrm{kg} / \mathrm{cm}^{2}$ & Mpa \\
\hline $\begin{array}{l}\text { Pasta de cemento conven- } \\
\text { cional }\end{array}$ & 2500 & 104,8 & 10,48 & 138,3 & 13,83 & 182,4 & 18,24 \\
\hline $\begin{array}{l}\text { Pasta de cemento con } 10 \% \\
\text { de hueso calcinado a } 600^{\circ} \mathrm{C} \\
\text { por } 1 \text { hora }\end{array}$ & 2500 & 99 & 9,9 & 122,4 & 12,24 & 135,6 & 13,56 \\
\hline $\begin{array}{l}\text { Pasta de cemento con } 10 \% \text { de } \\
\text { hueso calcinado a } 600^{\circ} \mathrm{C} \text { por } \\
2 \text { horas }\end{array}$ & 2500 & 98 & 9,8 & 129,3 & 12,93 & 173,3 & 17,33 \\
\hline $\begin{array}{l}\text { Pasta de cemento con } 10 \% \\
\text { de hueso calcinado a } 900^{\circ} \mathrm{C} \\
\text { por } 1 \text { hora }\end{array}$ & 2500 & 94,1 & 9,41 & 117 & 11,7 & 124 & 12,4 \\
\hline $\begin{array}{l}\text { Pasta de cemento con } 10 \% \text { de } \\
\text { hueso calcinado a } 900^{\circ} \mathrm{C} \text { por } \\
2 \text { horas }\end{array}$ & 2500 & 101 & 10,1 & 106,7 & 10,67 & 155,7 & 15,57 \\
\hline $\begin{array}{l}\text { Pasta de cemento con } 10 \% \\
\text { de hueso calcinado a } 1200^{\circ} \mathrm{C} \\
\text { por } 1 \text { hora }\end{array}$ & 2500 & 142,5 & 14,25 & 166,6 & 16,66 & 198,9 & 19,89 \\
\hline $\begin{array}{l}\text { Pasta de cemento con } 10 \% \\
\text { de hueso calcinado a } 1200^{\circ} \mathrm{C} \\
\text { por } 2 \text { horas }\end{array}$ & 2500 & 81 & 8,1 & 120,9 & 12,09 & 128 & 12,8 \\
\hline
\end{tabular}

Fuente: Pedraza et al. [20] 


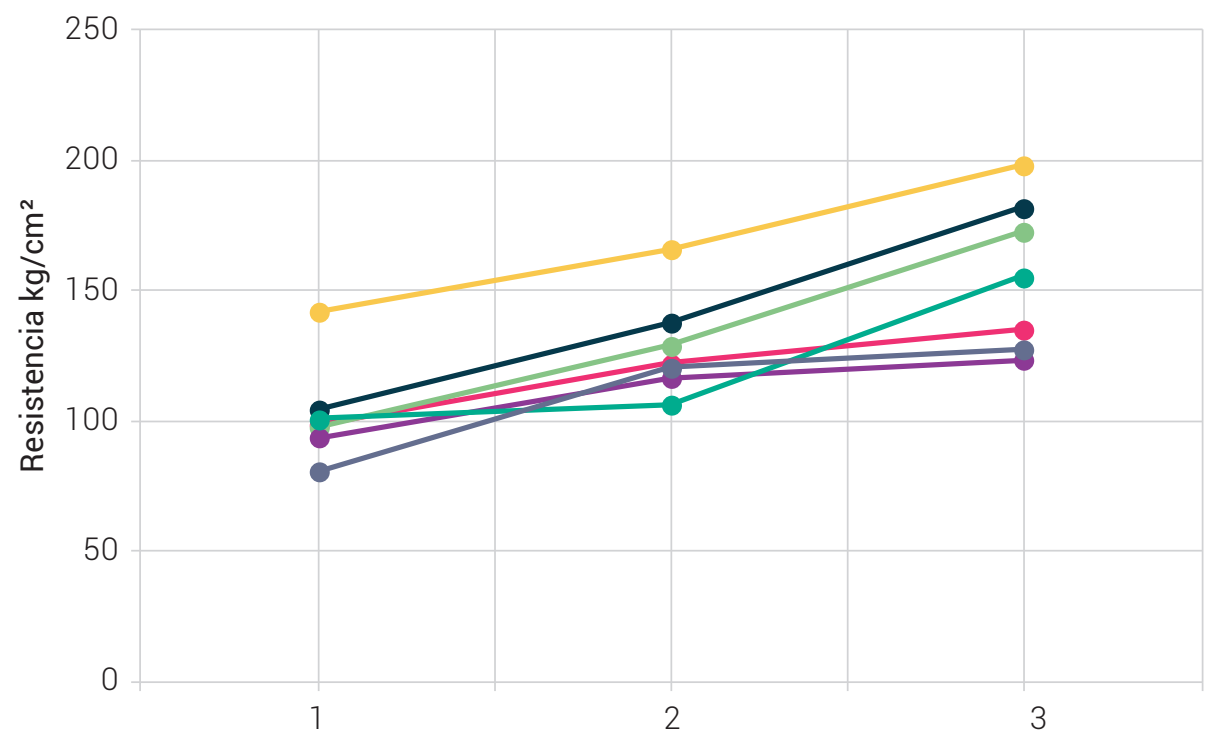

Días de curado

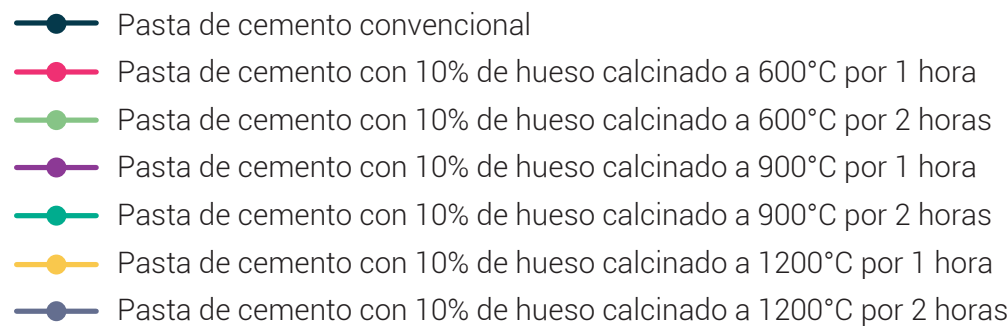

Figura 18. Prueba a compresión en pasta de cemento con $10 \%$ de hueso calcinado

Fuente: Pedraza et al. [20]

Tabla 22. Prueba a compresión en pasta de cemento con $15 \%$ de hueso calcinado

\begin{tabular}{|c|c|c|c|c|c|c|c|}
\hline \multirow{3}{*}{ Muestra } & \multirow{3}{*}{$\begin{array}{l}\text { Área } \\
\mathrm{mm}^{2}\end{array}$} & \multicolumn{6}{|c|}{ Resistencia a la compresión } \\
\hline & & \multicolumn{2}{|c|}{7 días } & \multicolumn{2}{|c|}{14 días } & \multicolumn{2}{|c|}{28 días } \\
\hline & & $\mathrm{kg} / \mathrm{cm}^{2}$ & Mpa & $\mathrm{kg} / \mathrm{cm}^{2}$ & Mpa & $\mathrm{kg} / \mathrm{cm}^{2}$ & Mpa \\
\hline $\begin{array}{l}\text { Pasta de cemento conven- } \\
\text { cional }\end{array}$ & 2500 & 104,8 & 10,5 & 138,3 & 13,8 & 182,4 & 18,2 \\
\hline $\begin{array}{l}\text { Pasta de cemento con } 15 \% \text { de } \\
\text { hueso calcinado a } 600^{\circ} \mathrm{C} \text { por } \\
1 \text { hora }\end{array}$ & 2500 & 101,9 & 10,2 & 108,0 & 10,8 & 172,1 & 17,2 \\
\hline $\begin{array}{l}\text { Pasta de cemento con } 15 \% \text { de } \\
\text { hueso calcinado a } 600^{\circ} \mathrm{C} \text { por } \\
2 \text { horas }\end{array}$ & 2500 & 60,0 & 6,0 & 95,9 & 9,6 & 115,3 & 11,5 \\
\hline
\end{tabular}




\begin{tabular}{|c|c|c|c|c|c|c|c|}
\hline \multirow{3}{*}{ Muestra } & \multirow{3}{*}{$\begin{array}{l}\text { Área } \\
\mathrm{mm}^{2}\end{array}$} & \multicolumn{6}{|c|}{ Resistencia a la compresión } \\
\hline & & \multicolumn{2}{|c|}{7 días } & \multicolumn{2}{|c|}{14 días } & \multicolumn{2}{|c|}{28 días } \\
\hline & & $\mathrm{kg} / \mathrm{cm}^{2}$ & Mpa & $\mathrm{kg} / \mathrm{cm}^{2}$ & Mpa & $\mathrm{kg} / \mathrm{cm}^{2}$ & Mpa \\
\hline $\begin{array}{l}\text { Pasta de cemento con } 15 \% \text { de } \\
\text { hueso calcinado a } 900^{\circ} \mathrm{C} \text { por } \\
1 \text { hora }\end{array}$ & 2500 & 47,0 & 4,7 & 115,8 & 11,6 & 145,2 & 14,5 \\
\hline $\begin{array}{l}\text { Pasta de cemento con } 15 \% \text { de } \\
\text { hueso calcinado a } 900^{\circ} \mathrm{C} \text { por } \\
2 \text { horas }\end{array}$ & 2500 & 95,0 & 9,5 & 97,0 & 9,7 & 160,2 & 16,0 \\
\hline $\begin{array}{l}\text { Pasta de cemento con } 15 \% \text { de } \\
\text { hueso calcinado a } 1200^{\circ} \mathrm{C} \text { por } \\
1 \text { hora }\end{array}$ & 2500 & 120,1 & 12,0 & 149,1 & 14,9 & 136,0 & 13,6 \\
\hline $\begin{array}{l}\text { Pasta de cemento con } 15 \% \text { de } \\
\text { hueso calcinado a } 1200^{\circ} \mathrm{C} \text { por } \\
2 \text { horas }\end{array}$ & 2500 & 76,0 & 7,6 & 108,1 & 10,8 & 126,0 & 12,6 \\
\hline
\end{tabular}

Fuente: Pedraza et al. [20]

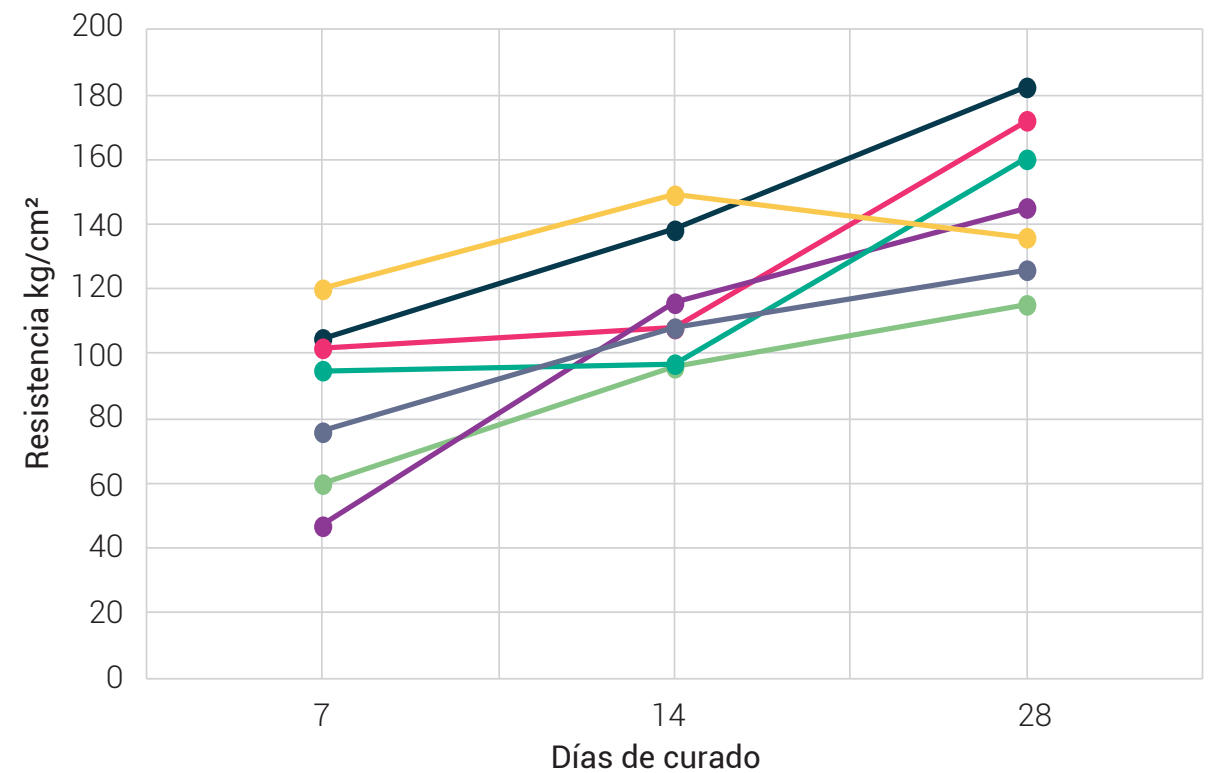

- Pasta de cemento convencional

- Pasta de cemento con $15 \%$ de hueso calcinado a $600^{\circ} \mathrm{C}$ por 1 hora

- Pasta de cemento con $15 \%$ de hueso calcinado a $600^{\circ} \mathrm{C}$ por 2 horas

- Pasta de cemento con $15 \%$ de hueso calcinado a $900^{\circ} \mathrm{C}$ por 1 hora

- Pasta de cemento con $15 \%$ de hueso calcinado a $900^{\circ} \mathrm{C}$ por 2 horas

- Pasta de cemento con $15 \%$ de hueso calcinado a $1200^{\circ} \mathrm{C}$ por 1 hora

- Pasta de cemento con $15 \%$ de hueso calcinado a $1200^{\circ} \mathrm{C}$ por 2 horas

Figura 19. Prueba a compresión en pasta de cemento con $15 \%$ de hueso calcinado

Fuente: Pedraza et al. [20] 
Tabla 23. Prueba a compresión en pasta de cemento con $20 \%$ de hueso calcinado

\begin{tabular}{|c|c|c|c|c|c|c|c|}
\hline \multirow{3}{*}{ Muestra } & \multirow{3}{*}{$\begin{array}{l}\text { Área } \\
\text { mm² }^{2}\end{array}$} & \multicolumn{6}{|c|}{ Resistencia a la compresión } \\
\hline & & \multicolumn{2}{|c|}{7 días } & \multicolumn{2}{|c|}{14 días } & \multicolumn{2}{|c|}{28 días } \\
\hline & & $\mathrm{kg} / \mathrm{cm}^{2}$ & Mpa & $\mathrm{kg} / \mathrm{cm}^{2}$ & Mpa & $\mathrm{kg} / \mathrm{cm}^{2}$ & Mpa \\
\hline Pasta de cemento convencional & 2500 & 104,8 & 10,5 & 138,3 & 13,8 & 182,4 & 18,2 \\
\hline $\begin{array}{l}\text { Pasta de cemento con } 20 \% \text { de hueso } \\
\text { calcinado a } 600^{\circ} \mathrm{C} \text { por } 1 \text { hora }\end{array}$ & 2500 & 119,6 & 12,0 & 125,3 & 12,5 & 139,2 & 13,9 \\
\hline $\begin{array}{l}\text { Pasta de cemento con } 20 \% \text { de hueso } \\
\text { calcinado a } 600^{\circ} \mathrm{C} \text { por } 2 \text { horas }\end{array}$ & 2500 & 70,5 & 7,1 & 81,3 & 8,1 & 127,8 & 12,8 \\
\hline $\begin{array}{l}\text { Pasta de cemento con } 20 \% \text { de hueso } \\
\text { calcinado a } 900^{\circ} \mathrm{C} \text { por } 1 \text { hora }\end{array}$ & 2500 & 111,8 & 11,2 & 128,1 & 12,8 & 140,8 & 14,1 \\
\hline $\begin{array}{l}\text { Pasta de cemento con } 20 \% \text { de hueso } \\
\text { calcinado a } 900^{\circ} \mathrm{C} \text { por } 2 \text { horas }\end{array}$ & 2500 & 129,9 & 13,0 & 130,5 & 13,1 & 155,7 & 15,6 \\
\hline $\begin{array}{l}\text { Pasta de cemento con } 20 \% \text { de hueso } \\
\text { calcinado a } 1200^{\circ} \mathrm{C} \text { por } 1 \text { hora }\end{array}$ & 2500 & 107,3 & 10,7 & 113,0 & 11,3 & 182,0 & 18,2 \\
\hline $\begin{array}{l}\text { Pasta de cemento con } 20 \% \text { de hueso } \\
\text { calcinado a } 1200^{\circ} \mathrm{C} \text { por } 2 \text { horas }\end{array}$ & 2500 & 97,2 & 9,7 & 150,6 & 15,1 & 147,0 & 14,7 \\
\hline
\end{tabular}

Fuente: Pedraza et al. [20]

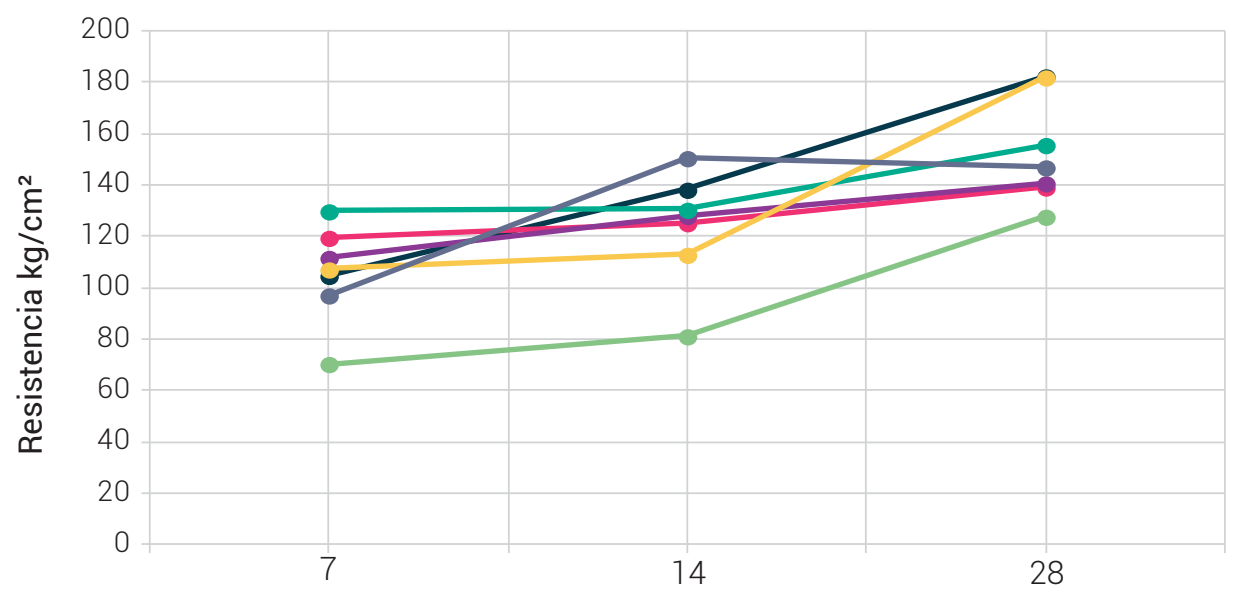

Días de curado

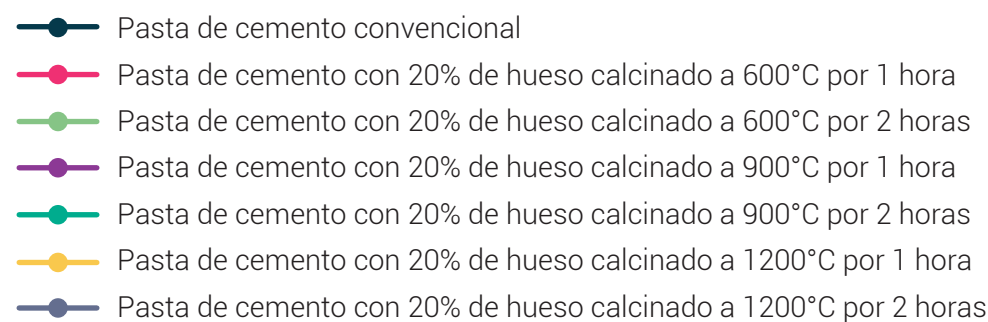

Figura 20. Prueba a compresión en pasta de cemento con $20 \%$ de hueso calcinado

Fuente: Pedraza et al. [20] 


\section{Discusión}

El principal tema a discutir es si el hueso es un material puzolánico, lo cual causaba contradicción entre los autores [12] y [13], por medio del mismo tipo de pruebas mecánicas y químicas. Estos dos autores se limitaron a hacer del tejido óseo un polvo, el cual no presenta ninguna propiedad adherente ni de endurecimiento, lo cual lo excluye de ser una puzolana, pero bajo el proceso de calcinación a diferentes tiempos de $600^{\circ} \mathrm{C}$ a $1200^{\circ} \mathrm{C}$ mostraba un cambio de propiedades fisicoquímicas que al ser humedecido y secado a temperatura ambiente, si presentaba un endurecimiento que permite percibir un grado promedio de adherencia similar al del cemento portland.

Este factor de confirmación en que separa el hueso en polvo del hueso calcinado convirtiéndolo en dos elementos inversos (puzolana y no puzolana), genera una pregunta puntual que es: ¿por qué si el hueso en polvo no es un elemento puzolánico en los artículos [10], [12], [14] arroja una resistencia superior a la del de la mezcla pura?

A parte de esto después se confirmó que le hueso calcinado a $1200^{\circ} \mathrm{C}$ es un material puzolánico, porque al superar 10\% de reemplazo sobre la mezcla, esta empieza a perder resistencia, lo cual equivale al mismo comportamiento que presentan los autores que utilizaron el hueso en polvo [7], [8], [11], [13].

Estas dos dudas dejan abierto el campo para que se siga profundizando en esta investigación para buscar la mejor manera de utilizar el hueso dentro de la mezcla de mortero, ya que esto es hasta ahora el inicio y no queda duda que dando un procesamiento adecuado a este material, este se puede convertir en el elemento ideal que se busca.

\section{Conclusiones}

El uso del hueso dentro de la mezcla de concreto sí es posible como agregado grueso, fino o parte del material cementante, pero este debe contar con un tratamiento previo a su utilización, especialmente para eliminar elementos orgánicos.

Las propiedades físicas del hueso calcinado a $1200^{\circ} \mathrm{C}$ son muy similares a las del cemento Portland e inclusive supera algunas de sus virtudes, lo que lo hace un material óptimo para hacer un reemplazo parcial del material cementante dentro de la mezcla, y puede brindar factores favorables en cuanto a resistencia y economía.

La pasta de cemento con hueso calcinado genera un aporte para la conservación de los recursos hídricos, ya que requiere un 3.08\% menos de agua que la pasta de cemento convencional. 
Aunque no todos los resultados de las pruebas a compresión sobre cubos de pasta de cemento fueron satisfactorios, es notorio que el hueso calcinado a $1200^{\circ} \mathrm{C}$ por una hora, aporta resistencia a la mezcla, específicamente cuando es reemplazado el cemento en un $10 \%$.

La reducción de los tiempos de fraguado en 45 minutos en la pasta de cemento con hueso calcinado es un factor de ahorro si por alguna condición se necesita de un aditivo para la aceleración del fraguado. De manera inversa, sería un factor en contra de la economía si se llega a necesitar un retardante en el tiempo de fraguado.

\section{Referencias}

[1] J.R Caeiro, P. González, D. Guede, "Biomecánica y hueso (yII): Ensayos en los distintos niveles jerárquicos del hueso y técnicas alternativas para la determinación de la resistencia ósea”. Revista de Osteoporosis y Metabolismo Mineral vol.5 no.2, abr./jun. 2013. [En línea]. Disponible en: http://scielo.isciii.es/scielo.php?script=sci_arttext\&pid=\$1889-836X2013000200007

[2] Curso de Fisiología: Capítulo 6. Sistema óseo Estructura y función del hueso. [En línea] Disponible en: http://www.iqb.es/cbasicas/fisio/cap06/cap6_3.htm

[3] Á. Mendoza, "Estudio de las propiedades mecánicas del sistema óseo". Revista Ingeniería e Investigación, no. 41 pp. 53-56. dic.1988, [En línea]. Disponible en: www.bdigital.unal.edu. co/23963/1/21059-71353-1-PB.pdf

[4] D. Sánchez, Tecnología del concreto y del mortero, 5a ed., Bogotá: Bhandar Editores Ltda, 2001.

[5] J. I. Mora, Diseño básico de concreto reforzado (vigas isostáticas). Bogotá: Universidad Piloto de Colombia, 2014.

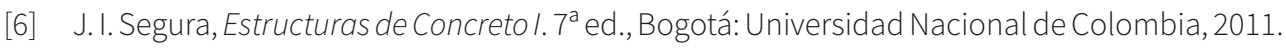

[7] F. Falade, E. Ikponmwosa y C. Fapohunda, "Flexural performance of foam concrete containing pulverised bone as partial replacement of cement". Maejo International Journal of Science and Technology, vol. 8, no.1, pp. 20-31, en. 2014. [En línea]. Disponible en: https://www.researchgate.net/publication/287634156_Flexural_performance_of_foam_concrete_containing_pulverized_bone_as_partial_replacement_of_cement 
[8] F. Falade, E. Ikponmwosa y C. Fapohunda, "Evaluation of strength relations in foamed aerated concrete ntaining pulverized bone (PB) as a partial replacement of cement", Engineering Review, vol. 38, no. 1, pp. 20-29, 2018. [En línea]. Disponible en: https://hrcak.srce.hr/192865

[9] S. Varma, M. Naidu, S. Mohan y D. Reddy, "An Effective Study on Utilizing Bone Powder Ash as Partial Replacement of Construction Material", International Journal of Innovative Technology and Research, vol. 4, no.3, pp. 3060-3062, .abr.- my. 2016. [En línea]. Disponible en: http:// www.ijitr.com/index.php/ojs/article/view/868

[10] A: Ahmad, S. Ahmad y K. Kashif, "Study of Concrete Properties using Bone Powder by Partial Replacement of Cement", Journal of Ceramics and Concrete Sciences, vol.2, no. 2, pp. 1-4, 2017. [En línea]. Disponible en: http://matjournals.in/index.php/JoCCS/article/view/1541

[11] N.Ogarekpe, J. Agunwamba, F. Idagu, E. Favour, O. Eteng, H. Ndem y E. Olok, "Suitability of burnt and crushed cow bones as partial replacement for fine aggregate in concrete", Nigeria Journal of Technology, vol 36, pp. 686-690, jul. 2017. [En línea]. Disponible en: https://www. researchgate.net/publication/318054838_Suitability_of_burnt_and_crushed_cow_bones_ as_partial_replacement_for_fine_aggregate_in_concrete

[12] J. Olawale, A.A. Adekunle y O. Ogundaini, "The effect of partial replacement of cement with bone ash and wood ash in concrete", Annal of Faculty Engineering Hunedoara-International Journal of Engineering vol. 24, no. 4, pp. 199-203, nov. 2016. [En línea]. Disponible en: http:// annals.fih.upt.ro/pdf-full/2016/ANNALS-2016-4-31.pdf

[13] F. Funso, E. Ikponmwosa y C. Fapohunda, "Low-cost construction through the use of pulverized bone foamed aerated concrete (PB-FAC), Civil and Environmental Research, vol. 3, no 10, pp. 107-113, 2013. [En línea]. Disponible en: https://www.iiste.org/Journals/index.php/CER/ article/view/7959

[14] D. Navya, "Evaluation of sustainable green concrete with partial replacement of cement by rice husk ash and partial replacement of coarse aggregate by crushed cattle bones, International Research Journal of Engineering and Technology (IRJET), vol. 4, no. 6, Jun. 2014. [En línea]. Disponible en: https://www.irjet.net/archives/V4/i6/IRJET-V4I6656.pdf

[15] F.N.Okoye y O.I Odumodu. "Investigation into the possibility of partial replacement of cement with bone powder in concrete production", International Journal of Engineering Research and Development, vol. 12, no. 10, oct. 2016. [En línea]. Disponible en: https://www.semanticscholar.org/paper/Investigation-Into-The-Possibility-of-Partial-of-in-Okoye-Odumodu/910770aa cd396adafc629741a5edc841cc217ba1 
[16] A. González. "De la cal al cemento Portland, Arquitectura Técnica Universidad de Alicante", [En línea]. Disponible en: https://html.rincondelvago.com/cal-y-cemento-portland.html

[17] C. Monroy, C. Ríos, J. D. Ospina, N. Ortiz y J. Villa, (oct. 2013), "Concreto de hueso calcinado concreto adictivo en 'cenizas de hueso calcinado'” [Prezi], [En línea]. Disponible en: https:// prezi.com/o59nsvtqunt9/concreto-de-hueso-calcinado/

[18] G. Somma y D. Rochinotti D., (2004), "Uso de la ceniza de huesos para suplantación mineral de rumiantes en pastoreo", Producción Animal. [En línea]. Disponible en: http://www.produccion-animal.com.ar/suplementacion_mineral/53-uso_ceniza_hueso.pdf

[19] Ministerio del Medio Ambiente, Vivienda y Desarrollo Territorial, "NSR-10 Título B - Cargas, Reglamento Colombiano de Construcción Sismo resistente”, pp. B-9 - B-19. [En línea]. Disponible en: https://www.idrd.gov.co/sitio/idrd/sites/default/files/imagenes/titulo-a-nsr100.pdf

[20] F. Pedraza, M. P. Riveira, E. V. y J. I. Mora, Evaluación de la resistencia a la compresión de un concreto hidráulico con reemplazo parcial de cemento por hueso bovino calcinado. [Proyecto de grado]. Universidad Piloto de Colombia, Bogotá, 2017.

[21] Instituto Nacional de Vías, "INV E-212-07 Contenido aproximado de materia orgánica en arenas usadas en la preparación de morteros o concretos”, pp. E212-1 a E212-3. [En línea]. Disponible en: ftp://ftp.unicauca.edu.co/Facultades/FIC/IngCivil/Especificaciones_Normas_ INV-07/Normas/Norma\%20INV\%20E-212-07.pdf

[22] Instituto Nacional de Vías, "INV E-302-07 Finura del cemento Portland método del aparato Blaine”, pp. E302-1 a E302-13. [En línea]. Disponible en: ftp://ftp.unicauca.edu.co/Facultades/ FIC/IngCivil/Especificaciones_Normas_INV-07/Normas/Norma\%20INV\%20E-302-07.pdf

[23] Instituto Nacional de Vías, "INV E-305-07 Tiempo de fraguado del cemento hidráulico método del aparato de Vicat”, pp. E305-1 a E302-5. [En línea]. Disponible en: ftp://ftp.unicauca.edu. co/Facultades/FIC/IngCivil/Especificaciones_Normas_INV-07/Normas/Norma\%20INV\%20 E-305-07.pdf

[24] Instituto Nacional de Vías, "INV E-323-07 resistencia a la compresión de morteros de cemento hidráulico", pp. E305-1 a E302-5. [En línea]. Disponible en: ftp://ftp.unicauca.edu. co/Facultades/FIC/IngCivil/Especificaciones_Normas_INV-07/Normas/Norma\%20INV\%20 E-323-07.pdf 
[25] J. Makunza, "Investigation on fired animal bones as aggregate remplacement in concrete", RILEM International workshop on performance-based specification and control of concrete durability, pp. 401-408, jun. 2014. [En línea]. Disponible en: http://demo.webdefy.com/rilemnew/wp-content/uploads/2016/10/61692f3dc92b5eee7c78caa0a49cf541.pdf

[26] M. Subrahmanyam, K. Dhana Sri, "Comparative study on effect of silica fume and animal bone on concrete by partial remplacement of coarse aggregate with animal bones and cement with flyash", International Journal of Engineering Research and Technology, vol. 5, no. 6, pp. 273-277, jun. 2016, [En línea]. Disponible en: file://C:/Users/ASUS/Downloads/ IJERTV5IS060366.pdf

[27] Ministerio del Medio Ambiente, Vivienda y Desarrollo Territorial, "NSR-10 Título C - Cargas, Reglamento Colombiano deConstrucción Sismoresistente”, pp.C-7-C-33. En línea]. Disponible en: https://www.idrd.gov.co/sitio/idrd/sites/default/files/imagenes/3titulo-c-nsr-100.pdf

[28] Icontec, "NTC 220. Determinación de la resistencia de morteros de cemento hidráulica usando cubos de 50mm o 50.8mm de lado" pp. 1-11, 2004.

[29] Icontec, "NTC 30 Cemento Portland. Clasificación y nomenclatura”, pp. 5-17, 1966. 